\title{
Ageing, human capital and demographic dividends with endogenous growth, labour supply and foreign capital
}

\section{Thomas Ziesemer $^{1}$ (D) - Anne von Gässler ${ }^{1}$}

Received: 1 May 2019 / Accepted: 28 April 2020 /Published online: 19 June 2020

(C) The Author(s) 2020

\begin{abstract}
We add endogenous labour supply to exogenous population growth in an Uzawa-Lucas endogenous growth model with international capital movements. Under non-linearity from a decreasing marginal product of labour in education and a positive human capital externality in output production, a combination of an estimated debt-interest relation and a realistic calibration of the model shows the following. (i) The demographic dividends from a fall in the population growth rate increase welfare in the short run and reduce it in the long run. (ii) A higher (lower) growth rate of the dependency ratio leads to a higher (lower) optimal level of education and technical change. (iii) Lower past cumulated savings lead to a higher foreign-debt/GDP ratio, higher interest rates, more education time and technical change, and more consumption in the future rather than the present. (iv) A higher depreciation rate of human capital through ageing has a stronger impact on growth rates than all other variables that could be associated with ageing and a good mitigating policy is to spend more time on education.
\end{abstract}

Keywords Ageing $\cdot$ Human capital $\cdot$ Endogenous growth $\cdot$ Open economy

JEL classification $\mathrm{F} 43 \cdot \mathrm{J} 11,24 \cdot \mathrm{O} 11 \cdot \mathrm{O} 33 \cdot \mathrm{O} 41$

\section{Introduction}

The fall in the population growth rates of OECD countries since the 1950 and early 1960 s is widely accepted to be the cause of the current threat of ageing, defined as the increase of the average age of the population and to be distinguished from the fact that

Thomas Ziesemer

T.Ziesemer@maastrichtuniversity.nl; Ziesemer@merit.unu.edu

1 Department: economics, Maastricht University, Tongersestraat 53, 6200MD Maastricht, Limburg, Netherlands 
old individuals die at an increasingly higher age in some countries. The threat comes from the expectation of a lower labour/population ratio, from the fear of having too low past savings, and the expected loss of human capital when the elderly retire. A crucial element in this explanation is the assumption that people are not responding strongly with working more. Working more could come from elderly employees retiring later, more hours per year of the young, male or female, full time or part time employees, and reductions of unemployment or increasing immigration (Bloom et al. 2010), or from spending less time in education. The lack thereof implies less contribution to pay-asyou-go systems and a heavier pressure on the savings of pension fund systems. The young are a decreasing share of the population though and the recent trend to retire later has run into stagnation at least in the Netherlands. Alternatively, or in addition, for any given amount of labour there could be a higher level or growth rate of the efficiency of labour, i.e. more technical progress. We focus on education and technical change and endogenous labour supply rather than all the details of labour supply sources.

The major aim of this paper is to find (i) the optimal reaction of the growth of the labour active in production or education, $L_{t}$, to an ageing population, and (ii) the optimal share of it in education or production. One important question is how the agents in the economy will allocate their time if no exogenous restrictions or misleading information from pension systems on the time spent in the active population are used in times of ageing: choosing more or less leisure, working more for output or spending more time in education? Moreover, times of ageing do generate the problem of a low dependency ratio and the labour allocation, and also of the effect of having saved too little pension funds in the past because of too optimistic information. We will also analyze how lower accumulated savings affect optimal decisions in the presence of imperfect international capital movements. Ageing may lead to a lower labour supply elasticity and we want to know what the impact of this might be for the growth rates and other variables. Last not least, an important question is how the economy reacts to an increase in the rate of depreciation of human capital when retirement leads to the loss of qualified persons in their workforce.

We will analyze the questions using the framework of a modified version of the open economy version of the Uzawa-Lucas model by Frenkel et al. (1996, chapter 15), which allows for international capital movements, but not migration or trade in goods. ${ }^{1}$ International capital movements are crucial because the ageing in China and India, the fastest growing regions, comes one or two decennia later than that of the OECD countries and is weaker in the USA (see Fehr et al. 2010; Narciso 2010; Mérette and Georges 2010). If asymmetric ageing generates asymmetric labour input growth, the marginal products of capital react differently, and capital will move. As the experience suggests that interest rates are increasing under higher foreign debt, we will modify the model also for this aspect. Other authors also have dealt with international capital movements, but they do not consider it in connection with endogenous growth. ${ }^{2}$ An

\footnotetext{
${ }^{1}$ Other authors may want to analyze similar questions using other endogenous growth models. The more wellknown ones though produce technical change using unskilled labour or exogenous human capital and are closed economy models with an additional sector for the production of intermediates. They too will require some adjustment before they can analyze questions of ageing. It will be interesting then to compare their results with ours.

${ }^{2}$ See Börsch-Supan et al. (2006), Attanasio et al. (2007), and Krüger and Ludwig (2007); Heijdra and Romp (2008) are an exception discussed below.
} 
important modification though is to distinguish between (exogenous) population and endogenous labour supply as required by our research question, because labour supply may react to ageing and its consequences. We will calibrate the model to the parameters in line with the estimation of two non-linear parts of the model. Due to a lower current (as opposed to earlier) growth rate of the population, the endogenized growth rate of the active part of the population will be lower too, in a way leading to a lower growth rate of the dependency ratio, and the agents in the economy will spend less time in education and generate less growth. The debt-dependent interest rate will be lower. The effect of too low past savings captured in the initial endowment of cumulated past savings compared to a higher value from a less sub-optimal behavior in the past, is a higher debt and a higher interest rate. This leads to a higher optimal time spent in education and higher growth of human capital as well as a shift of consumption into the future. In short, less labour supply growth and a lower level of capital lead to opposite effects on optimal education time and human capital growth. However, reduced labour supply is mainly a matter of the past to which we can react through optimal labour supply today, whereas too little pension capital is a problem of the present to which we can react only gradually by saving more, but more quickly through putting more time into education and human capital growth. Ageing may also come in the form of a changing wage elasticity of labour supply and a higher rate of depreciation of human capital capturing the loss of skilled workers, both with consequences for the allocation of time to education and output, and growth rates.

Only a few contributions of the endogenous growth type come close to what we are trying to do. Zhang et al. (2001) consider longer life expectancy of ageing workers. It leads to higher human capital driven growth in the case of lower fertility. The reason is a high preference for the number of children compared to that for their individual welfare. The positive effect on education enhances the growth rate. However, this result holds for fully funded or no social security, but the opposite holds for pay-as-you-go systems with defined and unchanged benefits unless the parameter constellation has a relatively high weight on the welfare of children; the authors prefer this last case. Moreover, if fertility declines in their model, because of a shift in the preference for the number of children, capturing the appearance of anti-conception, fertility falls, and human capital and growth rise in all pension systems considered (see their Eq. (14) in connection with either (16) or (23)). In Zhang et al. (2003) a high share of people reaching the pension age leads to majority voting in favour of little public education (absent private education) and a low physical/human capital ratio, implying low growth. These models have no human capital depreciation and therefore do not capture the loss of qualifications when workers retire. International capital movements are not related to savings. In the model by Boucekkine et al. (2002) ageing leads to higher life expectancy, more education, later retirement, and higher growth. However, unlike the Lucas model used below, the old, by assumption, do not have the opportunity to invest time in education ${ }^{3}$; they do not consider other ways to care for the old age like saving, borrowing and a leisure-labour choice before retirement. Therefore, it would not be obvious a priori whether or not more education is the optimal response to ageing. Cervellati and Sunde (2005) show that increasing life expectancy - in

\footnotetext{
${ }^{3}$ Bowlus et al. (2016) argue that in fact the old still invest in skills and Lang (2016) adds that this decreases with age.
} 
general an important aspect of ageing - may have led to more literacy around 1900 and more endogenous technical change at any human capital level. However, there is no population growth, no way of distinguishing between population and labour, or a dependency ratio as we need it for the analysis of ageing. Bonneuil and Boucekkine (2017) contribute the impact of the age structure on the choice of education and labour supply through a realistic survival law. They do so at the cost of dropping endogenous technical change, savings and international capital movements from the analysis, which are very important for our purpose. Cervellati and Sunde (2013) use a different survival law and add perfect domestic capital markets. Cervellati and Sunde (2015) link demographic features to a unified growth model. However, the richest countries have constant exogenous growth and there is no impact of international capital movements on interest rates. Gruescu (2006), Heijdra and Romp (2009a, b) and Boucekkine et al. (2013) also use a Lucas-type model. They all use Lucas' (1988) simplified version with a linear effect of time in education. ${ }^{4}$ As the answer to our question of putting labour more into education or more into working for output, we need a realistic marginal product and opportunity costs here. In Heijdra and Romp (2008, 2009a) savings and capital movements are allowed at a given interest rate. The interest rate is not reduced (increased) if less (more) labour leads to a lower (higher) marginal product of capital and capital flows out (in) as it happens to occur in our model. Boucekkine et al. (2013 provide a closed economy model in which all persons either work or are in education. Therefore, there is no labour/population ratio, which we want to consider, and borrowing more in times of higher growth of the population/labour ratios for the economy is not possible, unlike our model.

Next, there is a widely ignored set of overlapping generations models with human capital formation (see Choi and Shin 2015). They differ from ours in several respects. (i) The elasticity of production for time in human capital production is too high or too low, both by a factor 2.6 (see below). (ii) They are closed economy models missing the additional effects that come from capital in- and outflows aggravating ageing. (iii) They have a too low labour supply elasticity according to recent literature.

von Gaessler and Ziesemer (2016) provide a Lucas-type of endogenous growth model. They show (i) that there are decreasing returns to time input in human capital formation at an empirically derived rather than merely assumed elasticity; (ii) that a higher exogenous growth rate of ageing, based on exogenous growth rates of labour and population growth, also leads to more education and technical change. The advantage of exogenous population and labour growth rates is that one can make scenarios by assumption, including the inefficiently slow labour supply growth based on early retirement of the recent past in OECD countries (see also Prettner and Canning 2014). As some countries now abandon these policies, we want to look at optimal endogenous labour supply in connection with endogenous technical change. Ludwig et al. (2012) also consider endogenous labour supply and education but with exogenous productivity. Contributions to the literature, which are related merely to details of our paper, will be discussed below.

In short, all papers of the literature are missing some relevant elements. As technical change is an element of endogenous growth models it is a logical step of this paper to endogenize the choice of labour supply in an endogenous growth model with

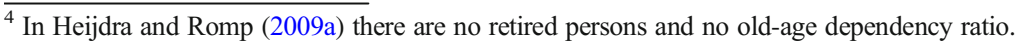


exogenous population growth in order to see what the optimal reaction to its change is in regard to labour supply, education and technical change.

Section 2 introduces the utility function with a Frisch-elasticity for labour supply in order to distinguish between labour and population. Section 3 looks at the data for education time because we have to adjust data for splitting of schooling and working time of apprentices; we analyze the dynamics of education time in order to obtained important information for the calibration. Section 4 introduces the estimated debtdependent interest rate function and shows the existence of a unique steady state for the whole model, which can be reduced to two equations for two variables, foreign debt and education time. Section 5 analyses the response to changes in the population growth rate, in particular the demographic dividends in the context of dynamic optimization, and the adjustment of ageing and education. Section 6 investigates the consequences of missing past savings. Section 7 captures ageing modeled as a higher Frisch parameter or as a higher rate of depreciation of human capital, showing that the latter has much stronger effects than the former and requires more time spent on education. Section 8 summarizes and concludes.

\section{The model}

The endogenization of the choice of participation in the active population, ${ }^{5} L_{t}$, as a share of the total population, $N_{t}$, is conducted by introducing the relation between the active population and the entire population, $L_{t} / N_{t}$, in the utility function. This is the inverse of the dependency ratio in the form $1+D_{t}=\frac{N_{t}}{L_{t}}$, or $D_{t}=\frac{N_{t}-L_{t}}{L_{t}}$, which is the ratio of all dependent persons, not only the old, per worker. It has a Frisch parameter of labour supply, $\vartheta$, which captures the effect of a change in the share of the active population. Being involved in the active population or dedicating a high share of the population to the active population, has a negative effect on utility. On the other hand, being inactive, or involving few labour resources in the active population, will lead to low output per capita, which will result in low consumption and, hence, low utility. Hence, there must be an optimal labour supply. Consumers are assumed to maximize their utility function, which is assumed to be

$$
U_{t}=\sum_{t=0}^{\infty} \beta^{t} N_{t}\left(\frac{c_{t}^{1-\sigma}}{(1-\sigma)}-\xi \frac{\left(\frac{L_{t}}{N_{t}}\right)^{1+\vartheta}}{1+\vartheta}\right)
$$

The expression above shows the utility function of the entire population. Here $0<\beta<1$ is the subjective discount factor; $\sigma>0$ is the intertemporal elasticity of substitution for consumption with $\sigma \neq 1$ in order to avoid division by zero; $\vartheta>0$ is the Frisch elasticity parameter for labour supply; $\xi>0$ is a parameter, which measures the disutility of participation in the active population relative to the consumption part of utility; $c_{t}$ is individual consumption. $L_{t}$ is the size of the population active in work or leisure as in

\footnotetext{
${ }^{5}$ Usually the interpretation is "labour force participation". This interpretation is not feasible in this model as the active population consists of the actual labour force and people in education.
} 
the training model of Wallenius (2011). $N_{t}$ is the size of the entire population normalized to unity in Wallenius (2011) and Malik (2013) both using the same utility function. ${ }^{6}$ The economy consists, by assumption, of output-producing firms and labour- and capital-supplying consumers. Output is formed by a Cobb-Douglas production function and is determined by physical capital, $K_{t}$, and efficient labour. Efficient labour, $\left(1-e_{t}\right) h_{t} L_{t}$, is the product of individual human capital, $h_{t}$, and the part of the active population, which is not in education, $\left(1-e_{t}\right) L_{t}$. The households decide between spending their time in production $\left(1-e_{t}\right)$ for immediate output generation and education, $e_{t}$, to increase their productivity for later production. A human capital externality is added as, $\bar{h}_{t}^{\epsilon}$, modelled after Lucas (1988), to include the influence of the average skill level on the economy. This forms the production function

$$
Y_{t}=A\left(K_{t}\right)^{1-\alpha}\left(\left(1-e_{t}\right) h_{t} L_{t}\right)^{\alpha} \bar{h}_{t}^{\epsilon}
$$

The demand for physical and human capital is determined in a firm, which maximizes profits:

$$
\begin{gathered}
\max _{\left(1-e_{t}\right), K_{t}} \pi=\mathrm{A}\left(K_{t}\right)^{1-\alpha}\left(\left(1-e_{t}\right) h_{t} L_{t}\right)^{\alpha} \bar{h}_{t}^{\epsilon}-\omega_{t}\left(1-e_{t}\right) h_{t} L_{t}-r_{k t} K_{t} \\
\omega_{t}=\frac{\alpha Y_{t}}{\left(1-e_{t}\right) h_{t} L_{t}} \\
r_{k t}=(1-\alpha) \frac{Y_{t}}{K_{t}}
\end{gathered}
$$

Equations (2) and (3) represent first-order conditions, equating marginal productivity of labour and capital to wages for efficient labour and rental rates. Consumers face the following budget constraint:

$$
N_{t} c_{t}+K_{t+1}-\left(1-\delta_{k}\right) K_{t}=\omega_{t}\left(1-e_{t}\right) h_{t} L_{t}+r_{k t} K_{t}+B_{t+1}-\left(1+r\left(\frac{B_{t}}{Y_{t}}\right)\right) B_{t}
$$

The right-hand side of Eq. (4) represents the total income which is the income from labour, $\omega_{t}\left(1-e_{t}\right) h_{t} L_{t}$, the income from capital rent, $r_{k t} K_{t}$, and the foreign debt from outside the economy's borders minus the interest and re-payments, $B_{t+1}-\left(1+r\left(\frac{B_{t}}{Y_{t}}\right)\right) B_{t}$. $r\left(\frac{B_{t}}{Y_{t}}\right)$ is the debt-dependent interest rate. The left-hand side of Eq. (4) represents the spending on consumption, $N_{t} c_{t}$, and capital investment, $K_{t+1}-\left(1-\delta_{k}\right) K_{t}$. Output is the numéraire, and capital, consumption, wages and debt are measured in the same unit.

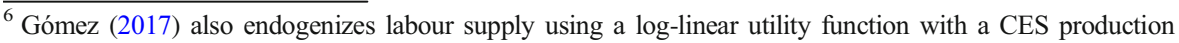
function for a closed economy with constant population for a different purpose.
} 
For the budget constraint to hold, both sides must be equal at all times. We do not model a government or a pension system separately. The firm has zero profits by Euler's theorem because of constant returns to scale (Hellwig and Irmen 2001). The household budget and that of the country are balanced through the inclusion of debt. Consumption is not differentiated in regard to age or (not) working. This is implicit in the assumption of equal consumption of all for a given point in time.

Human capital formation is determined by the time share spent in education, $e_{t}$, with diminishing or constant returns to scale. Equation (5) shows how human capital is formed with the productivity parameter, $\gamma \leq 1$, the knowledge efficiency coefficient, $F$, and depreciation of human capital, $\delta_{h}{ }^{7}$

$$
h_{t+1}=F e_{t}^{\gamma} h_{t}+\left(1-\delta_{h}\right) h_{t}
$$

Uzawa (1965) and Lucas (1988) use a zero depreciation rate. But for the treatment of ageing the increase in the loss of qualifications of workers can be captured by an increase in this depreciation rate and therefore it must be included and correspondingly the calibration is different than without it. We assume that h-terms on the right-hand side have exponent unity in line with recent evidence favouring fully over semiendogenous growth theory (Ha and Howitt 2007; Madsen 2008; Ziesemer 2020). Consumers maximize their utility subject to their budget constraint, Eq. (4), and the human capital formation function, Eq. (5), given the parameters and initial values of $h_{t}$, and $K_{t}-B_{t}$. The maximization program for the consumers is:

$$
\begin{aligned}
& \max _{c_{t}, e_{t}, L_{t}, B_{t+1}, K_{t+1}, h_{t+1}} \sum_{t=0}^{\infty} \beta^{t} \\
& \left(N_{t}\left(\frac{c_{t}^{1-\sigma}}{(1-\sigma)}-\xi \frac{\left(\frac{L_{t}}{N_{t}}\right)^{1+\vartheta}}{1+\vartheta}\right)-\mu_{t}\left[N_{t} c_{t}+K_{t+1}-\left(1-\delta_{k}\right) K_{t}-\omega_{t}\left(1-e_{t}\right) h_{t} L_{t}-r_{k t} K_{t}-B_{t+1}+\left(1+r\left(\frac{B_{t}}{Y_{t}}\right)\right) B_{t}\right]-\mu_{h t}\left[h_{t+1}-F e_{t}^{\gamma} h_{t}-\left(1-\delta_{h}\right) h_{t}\right]\right)
\end{aligned}
$$

The first-order conditions for an interior solution ${ }^{8}$ are as follows:

$$
\begin{gathered}
\mathrm{c}_{t}: c_{t}^{-\sigma}=\mu_{t} \\
\mathrm{e}_{t}: \quad \mu_{t} \omega_{t} L_{t}=\mu_{h t} F \gamma e_{t}^{\gamma-1}
\end{gathered}
$$

\footnotetext{
${ }_{7}^{7}$ Uzawa (1965) uses a more general strictly concave function $\varphi(e)$ and Lucas (1988) uses also this function in the first instance and the simplification $\gamma=1$ only later for simplicity of finding an explicit solution for the model.

${ }^{8}$ Below, we derive a unique solution of the model for $e, b=B / Y$ and the consumption shares, and all the growth rates. For that, we do not need an assumption for $\xi$. Given the right-hand side of (8), a sufficiently high value for $\xi$ can ensure $L(t)<N(t)$. This allows for both cases, $L$ growing faster or slower than $N$. We do not consider the growth path for the corner solution $L=N$. This is what all papers do that do not distinguish between population and labour. With a unique solution of a consumption share below unity, a no-Ponzi-game (NPG) condition would be redundant. The reason is that a high debt is punished through a high interest rate. Without that, infinite consumption through infinite borrowing would be possible. NPGs and other approaches (Ziesemer 1995,p.36-38) would be needed to prevent this. It can be shown that the utility function has a finite integral, and hence a maximum exists.
} 


$$
\begin{gathered}
\mathrm{L}_{t}: \xi N_{t}^{-\vartheta} L_{t}^{\vartheta}=\mu_{t} \omega_{t}\left(1-e_{t}\right) h_{t} \\
\mathrm{~B}_{t+1}: \mu_{t}=\beta \mu_{t+1}\left(1+r\left(\frac{B_{t+1}}{Y_{t+1}}\right)\right)+\beta \mu_{t+1} \frac{B_{t+1}}{Y_{t+1}} r^{\prime}\left(\frac{B_{t+1}}{Y_{t+1}}\right) \\
\mathrm{K}_{t+1}: \mu_{t}=\beta \mu_{t+1}\left(1-\delta_{k}+r_{k t+1}\right) \\
\mathrm{h}_{t+1}: \mu_{h t}=\beta\left[\mu_{t+1} \omega_{t+1}\left(1-e_{t+1}\right) L_{t+1}+\mu_{h t+1} F e_{t+1}^{\gamma}+\left(1-\delta_{h}\right) \mu_{h t+1}\right]
\end{gathered}
$$

The following transversality conditions hold by assumption:

I.

$$
\lim _{t \rightarrow \infty} \beta^{t} \mu_{t} K_{t}=0
$$

II.

$$
\lim _{t \rightarrow \infty} \beta^{t} \mu_{h t} h_{t}=0
$$

The system of Eqs. (1)-(11) determine the eleven endogenous variables, $Y_{t}, K_{t}, L_{t}, h_{t}$, $e_{t}, \omega_{t}, r_{k t}, c_{t}, B_{t}, \mu_{t}$, and $\mu_{h t}$. The rates of return to physical capital, bonds, human capital and, future labour input can be derived. They are displayed in Eqs. (12a-e).

$$
\begin{gathered}
\frac{1}{\beta}\left(\frac{c_{t+1}}{c_{t}}\right)^{\sigma}=\frac{\mu_{t}}{\beta \mu_{t+1}}=R_{B t+1}=R_{K t+1}=R_{H t+1}=R_{L t+1} \\
R_{B t+1}=1+r\left(\frac{B_{t+1}}{Y_{t+1}}\right)\left(1+\eta_{r b}\right) \\
R_{K t+1}=1-\delta_{k}+(1-\alpha) \frac{Y_{t+1}}{K_{t+1}} \\
R_{H t+1}=\left(1+g_{\omega}\right)\left(1+g_{L}\right) F \gamma e_{t}^{\gamma-1}\left[1-e_{t+1}+\frac{1}{\gamma} e_{t+1}+\frac{1-\delta_{h}}{F \gamma e_{t+1}^{\gamma-1}}\right] \\
R_{L t+1}=\frac{\left(1+g_{N}\right)^{\vartheta}\left(1+g_{\omega}\right)\left(1+g_{1-e}\right)\left(1+g_{h}\right)}{\beta\left(1+g_{L}\right)^{\vartheta}}
\end{gathered}
$$

The first part of (12a) is derived from (6), where the other equivalencies on the right hand side follow from (12b-e), obtained by rearranging Eqs. (8), (9), (10) and (11) to solve for $\frac{\mu_{t}}{\beta \mu_{t+1}}$. Equation (12b) follows straight forwardly from (9) with 
$\eta_{r b}=\frac{B_{t+1}}{Y_{t+1}} \frac{r^{\prime}\left(\frac{B_{t+1}}{Y_{t+1}}\right)}{r\left(\frac{B_{t+1}}{Y_{t+1}}\right)} ;(12 \mathrm{c})$ is derived from (10) where $r_{k t+1}$ is replaced by the expression in (3); Eq. (12d) is derived from (11) where $\mu_{h t}$ is replaced by the relation in (7). The relation (12e) for the rate of return of the active population size is derived from (8).

If $\frac{B_{t}}{Y_{t}}, r\left(\frac{B_{t}}{Y_{t}}\right)$ and its elasticity are assumed to be constant this leads to a constant growth rate of $c_{t}$ through $(12 \mathrm{a}, \mathrm{b})$ :

$$
\mathbf{1}+\boldsymbol{g}_{c}=\left[\beta\left(1+r\left(\frac{B_{t}}{Y_{t}}\right)\left(1+\eta_{r b}\right)\right)\right]^{\frac{1}{\sigma}}
$$

From this follow constant $R_{K t+1}$ and $R_{H t+1}$ and $R_{L t+1}$ in (12c), (12d) and (12e) respectively. Constancy of $\frac{Y_{t+1}}{K_{t+1}}$ follows directly from constant $R_{K t+1}$ in (12c), which can be expressed as: $\frac{Y_{t+1}}{K_{t+1}}=A\left(\frac{K_{t+1}}{\left(1-e_{t+1}\right) h_{t+1}^{1+\frac{\epsilon}{\alpha}} L_{t+1}}\right)^{-\alpha}$. This implies equality of the growth rates of the numerator and the denominator:

$$
1+g_{Y}=1+g_{K}=\left(1+g_{1-e}\right)\left(1+g_{h}\right)^{1+\frac{\epsilon}{\alpha}}\left(1+g_{L}\right)
$$

Equation (12c) $)^{\mathrm{I}}$ shows that the growth rates of output and capital depend on the change of time spent in production, the growth rate of human capital, and the growth rate of labour supply.

The growth rate of wages is crucial to determine the rates of return to labour and human capital. Wages are determined from Eq. (2):

$$
1+g_{\omega}=\frac{1+g_{Y}}{\left(1+g_{1-e}\right)\left(1+g_{h}\right)\left(1+g_{L}\right)}
$$

Inserting $(12 \mathrm{c})^{\mathrm{I}}$ into $(2)^{\mathrm{I}}$ leads to:

$$
1+g_{\omega}=\left(1+g_{h}\right)^{\frac{\epsilon}{\alpha}}
$$

Together with the human capital formation function (5), this shows that $g_{\omega}$ is constant if $e_{t}$ is constant (i.e. if $g_{e}=0$ ). Equation (2) ${ }^{\mathrm{II}}$ shows that the development of wages per labour efficiency unit depends solely on that of human capital. Wage growth per labour efficiency unit is only positive if the externalities are positive.

The growth rate of the active population, $\left(1+g_{L}\right)$, can be derived from Eq. (12e). With the expression in Eq. (12b), $R_{L t+1}$ can be replaced by $1+r\left(\frac{B_{t}}{Y_{t}}\right)\left(1+\eta_{r b}\right)$. Plugging Eq. (2) ${ }^{\mathrm{II}}$ into Eq. (12e), and thus eliminating $\left(1+g_{\omega}\right)$ leads to

$$
\left(1+g_{L}\right)=\left(1+g_{N}\right)\left(\frac{\left(1+g_{h}\right)^{1+\frac{\epsilon}{\alpha}}\left(1+g_{1-e}\right)}{\beta\left(1+r\left(\frac{B_{t}}{Y_{t}}\right)\left(1+\eta_{r b}\right)\right)}\right)^{\frac{1}{\vartheta}}
$$


From $(12 \mathrm{c})^{\mathrm{I}}$ and $(12 \mathrm{e})^{\mathrm{I}}$ we find the growth of the GDP per capita of the population.

$$
\frac{1+g_{Y}}{1+g_{N}}=\left[\left(1+g_{h}\right)^{1+\frac{\epsilon}{\alpha}}\right]^{1+\frac{1}{\vartheta}}\left(\frac{1}{\beta\left(1+r\left(\frac{B_{t}}{Y_{t}}\right)\left(1+\eta_{r b}\right)\right)}\right)^{\frac{1}{\vartheta}}
$$

For given education time $e$, human capital growth rate $g_{h}$ and interest rate $r$ or debt $b$, lower population growth translates one-to-one into lower labour growth. For a constant interest rate and population growth rate, the steady state growth rate of labour depends on the endogenous development of individual human capital, and through this on time spent in education or production. Because the time spent in production, $\left(1-e_{t}\right)$, can by assumption not exceed 1 , its growth rate cannot be stable at any other value than zero. Equation $(12 \mathrm{e})^{\mathrm{I}}$ shows that if the choice of the size of labour is endogenized through negative utility associated with labour supply, the steady state growth rate of labour depends on time spent in education. If time spent in education and the interest rate are constant, so is $\left(1+g_{L}\right)$. For positive values of the Frisch parameter, the fraction in parenthesis will determine whether we have $g_{L}<g_{N}$. If the denominator including the discount factor and the interest rate is larger (smaller) than the numerator, this will (not) be the case.

In order to find the optimal time spent in education, we have to derive the dynamics of $e_{t}$. We do this by relating $e_{t}$ and $e_{t+1}$ to only exogenous variables. The main equation used is Eq. (12d). To show how the rate of return of human capital relates to time spent in education only, $\left(1+g_{\omega}\right)$ can be replaced in Eq. (12d) using Eq. (2) ${ }^{\mathrm{II}}$ and Eq. (5):

$$
R_{H t+1}=\left(F e_{t}^{\gamma}+\left(1-\delta_{h}\right)\right)^{\frac{\epsilon}{\alpha}}\left(1+g_{L}\right) F \gamma e_{t}^{\gamma-1}\left[\left(1-e_{t+1}\right)+\frac{1}{\gamma} e_{t+1}+\frac{\left(1-\delta_{h}\right)}{F \gamma e_{t+1}^{\gamma-1}}\right]
$$

Next, the endogenous variables $g_{L}$ and $g_{h}$ are replaced. With Eq. $(12 \mathrm{e})^{\mathrm{I}}$ replacing the growth rate of the labour force, $\left(1+g_{L}\right)$, Eq. $(12 d)^{\mathrm{I}}$ becomes

$$
R_{H t+1}=\left(1+g_{h}\right)^{\frac{\epsilon}{\alpha}}\left(1+g_{N}\right)\left(\frac{\left(1+g_{h}\right)^{1+\frac{\epsilon}{\alpha}}\left(1+g_{1-e}\right)}{\beta\left(1+r\left(\frac{B_{t}}{Y_{t}}\right)\left(1+\eta_{r b}\right)\right)}\right)^{\frac{1}{\gamma}} F \gamma e_{t}^{\gamma-1}\left[\left(1-e_{t+1}\right)+\frac{1}{\gamma} e_{t+1}+\frac{\left(1-\delta_{h}\right)}{F \gamma e_{t+1}^{\gamma-1}}\right]
$$

Replacing $\left(1+g_{h}\right)=F e_{t}^{\gamma}+\left(1-\delta_{h}\right)$ and $\left(1+g_{1-e}\right)=\frac{1-e_{t+1}}{1-e_{t}}$ yields:

$$
\begin{array}{r}
R_{H t+1}=\left(F e_{t}^{\gamma}+\left(1-\delta_{h}\right)\right)^{\frac{\varepsilon(1+\gamma)+\alpha}{\gamma \alpha}}\left(1+g_{N}\right)\left(\frac{1-e_{t+1}}{1-e_{t}}\right)^{\frac{1}{\gamma}}\left(\frac{1}{\beta\left(1+r\left(\frac{B_{t}}{Y_{t}}\right)\left(1+\eta_{r b}\right)\right)}\right)^{\frac{1}{\gamma}} \\
F \gamma\left[e_{t}^{\gamma-1}-e_{t}^{\gamma} \frac{e_{t+1}}{e_{t}}+e_{t}^{\gamma} \frac{1}{\gamma} \frac{e_{t+1}}{e_{t}}+\left(\frac{e_{t}}{e_{t+1}}\right)^{\gamma-1} \frac{\left(1-\delta_{h}\right)}{F \gamma}\right]
\end{array}
$$


This relates $e_{t}$ and $e_{t+1}$ to the interest rate and exogenous variables and parameters. $\frac{e_{t+1}}{e_{t}}$ can then be replaced by $1+g_{e}$. Since $1+g_{e}=\frac{e_{t+1}}{e_{t}} \leftrightarrow e_{t+1}=\left(1+g_{e}\right) e_{t}$, the expression $\left(\frac{1-e_{t+1}}{1-e_{t}}\right)^{\frac{1}{\vartheta}}$ thus becomes $\left(\frac{1-\left(1+g_{e}\right) e_{t}}{1-e_{t}}\right)^{\frac{1}{\vartheta}}$. This leads to:

$$
\begin{array}{r}
R_{H t+1}=\left(F e_{t}^{\gamma}+\left(1-\delta_{h}\right)\right)^{\frac{\epsilon(1+\theta)+\alpha}{\gamma \alpha}}\left(1+g_{N}\right)\left(\frac{1-\left(1+g_{e}\right) e_{t}}{1-e_{t}}\right)^{\frac{1}{\gamma}}\left(\frac{1}{\beta\left(1+r\left(\frac{B_{t}}{Y_{t}}\right)\left(1+\eta_{r b}\right)\right)}\right)^{\frac{1}{\gamma}} \\
F \gamma\left[e_{t}^{\gamma-1}-e_{t}^{\gamma}\left(1+g_{e}\right)+e_{t}^{\gamma} \frac{1}{\gamma}\left(1+g_{e}\right)+\left(\frac{1}{1+g_{e}}\right)^{\gamma-1} \frac{\left(1-\delta_{h}\right)}{F \gamma}\right]
\end{array}
$$

Because of the relations in Eqs. (12b) and (12a), $R_{H t+1}$ equals $1+r\left(\frac{B_{t}}{Y_{t}}\right)\left(1+\eta_{r b}\right)$; if the interest rate is constant, the both sides of Eq. (12d) $)^{\mathrm{III}}$ is constant as well. This is the dynamic equation that determines how $e_{t}$ develops over time, depending on the interest rate, the population growth rate and several parameters. With help of this equation, we can analyze the stability of $e_{t}$. Unfortunately, the above expression cannot be solved for $e_{t}$, or $g_{e}$ analytically. If we could solve for the growth rate of $e$, the function probably would be non-linear in $e, 1+r$ and $1+g_{N}$. The next section takes an empirical approach to this relation.

\section{The dynamics of education time in fourteen OECD countries}

In order to make reasonable assumptions for the parameters of the calibrated model we approach the non-linear relation $(12 \mathrm{~d})^{\mathrm{III}}$ by of $e$ on the linear, quadratic and cubic terms of $\log (e(-1)), \log (1+r)$ and $\log \left(1+g_{N}\right)$ and dropping the insignificant ones. For education time data we add up regular schooling, and on-the-job-training all from OECD iLibrary, ISCED levels 0-6, and vocational training from EUROSTAT 2005 and 2010 for Europe, which we use to construct a markup for all years; for Australia, Canada, and the USA we use UK mark ups. From the time of apprentices, which the statistics mostly count fully as schooling time, we shift $40 \%$ to working time and out of education time in order to bring the data in line with the concept of the production functions of the Uzawa-Lucas model. The data range goes from 0.284 to 0.518 with a panel mean of 0.344 . World Development Indicators provide data for real interest rates and population growth rates. We estimate the equation using Fully Modified OLS and the orthogonal deviation version of system GMM. With FMOLS we lose observations for three countries from the sample though. The result for system GMM is ( $p$-values in parentheses):

$$
\begin{aligned}
d(\log (\mathrm{e}))= & 4.32+\frac{(14.95-1)}{(0.011)} \times \log (\mathrm{e}(-1))+\underset{(0.016)}{14.35} \times(\log (\mathrm{e}(-1)))^{2} \\
& +\underset{(0.016)}{4.8} \times(\log (\mathrm{e}(-1)))^{3} \begin{array}{c}
-1.2 \\
(0.067)
\end{array} \times \log (1+\mathrm{gN})+\begin{array}{c}
1.148 \\
(0.130)
\end{array} \\
& \times(\log (1+\mathrm{r}))^{2}
\end{aligned}
$$


Period: 1988-2010; countries $14^{9}$; obs: $158 ; \mathrm{p}(\mathrm{J})=0.067 .^{10}$

We plot the result in $\mathrm{ge}_{\mathrm{e}}$-e plane using the values of $\mathrm{g}_{\mathrm{N}}=0.002$, and $\mathrm{r}=0.05$ as in the calibration below. Figure 1 shows the result. It has a steady state near $\mathrm{e}^{*}=0.365$, slightly higher than the panel mean of 0.34 . For FMOLS (pooled, weighted) it would be near 0.358 . By far most of the observations are between 0.28 and 0.42 . In this area, we have an inverted $u$-shape in Fig. 1. The cubic term just serves to mitigate the strictly symmetric structure of a quadratic function. This empirical result suggests that for calibration we should use parameter values that yield the inverted u-shape of the $g_{e}-e$ relation as in the data range of Fig. 1.

\section{Debt dynamics and existence of a steady state}

Because of the $\left(\frac{1-\left(1+g_{e}\right) e_{t}}{1-e_{t}}\right)^{\frac{1}{\vartheta}}$ term in Eq. $(12 \mathrm{~d})^{\mathrm{III}}$, we refrain from a full analytical analysis of Eq. (12d) $)^{\mathrm{III}}$. We work in the first instance with a population growth rates $g_{N}=0.002$. The Frisch parameter, $\vartheta$, is set to 3 in line with the traditional assumption of a low labour supply elasticity, $1 / \vartheta=0.33$, which is close to the vertical labour supply curve of neoclassical growth models. However, Chetty et al. (2011), Wallenius (2011) and Peterman (2016) have provided reasons and estimates suggesting higher values of the labour supply elasticities of $0.75,1,25$ and 3 . Below, we will vary this elasticity in order to see the effect of high and low values. Other parameter values are chosen to get to $g_{h}=0.013$ close to that of Denison according to Lucas (1988) because of the higher time share in education, and macroeconomic growth rates roughly in line with the panel average of the 14 OECD countries: $F=0.055, \alpha=0.6, \gamma=0.268, \delta_{h}=0.03, \epsilon=0.834$, $\beta=0.982, \sigma=1.06$ and $\delta_{k}=0.03$.

The assumption for the spillover parameter is twice as large as that by Lucas (1988) because he uses $\gamma=1$, almost four times as high as ours; the lower marginal product of time spent in education in our version of the model requires a higher externality in our model to calibrate the parameters roughly to the empirical growth rates. Einarsson and Marquis (1996) discussed reasons why the externality parameter may be 0.6 in the model with $\gamma=1$ rather than 0.42 assumed by Lucas. With the lower value for $\gamma$ it is therefore plausible also from this perspective to have an even higher externality parameter. In comparison with the set-up of de la Fuente and Doménech (2006), $h^{\alpha}$ is total factor productivity and $h^{\varepsilon}$ is the human capital term; our value of 0.834 is then

\footnotetext{
${ }^{9}$ The countries are Australia, Canada, Denmark, Spain, Finland, France, Germany, Greece, Ireland, Italy, the Netherlands, Sweden, the UK and the US.

${ }^{10} \mathrm{~J}$ is the Hansen-Sargan statistic and $\mathrm{p}(\mathrm{J})$ the corresponding $p$ value, which should not be too low through a too high J-statistic (Davidson and McKinnon 2004), which would go against the hypothesis of having a chisquare distribution, and not too high through a too low J-statistic, the latter indicating that instruments have little effect (Roodman 2009). 2SLS instrument weighting matrix; Period SUR (PCSE) standard errors \& covariance (d.f. corrected). Instrument specification: current interest and population growth variable because a Durbin-Wu-Hausman test rejects endogeneity, and lag (-2) for each education regressor; time dummies and constant added to instrument list. The variance ratio, the square of the standard deviation of fixed effects and the residuals of the estimation, which was set to unity in the Monte Carlo studies supporting System GMM, is $v r=(0.019944 / 0.015093)^{2}=1.75$. According to Bun and Windmeijer $(2010$; Table 6$)$ this would cause a bias for low $T$, but not for $T=23$ as we have here at best; for $T=11$ as we have here on average, their Table 6 shows that the bias may well be close zero for $\mathrm{vr}=1.75$. However, they do not include other regressors besides the lagged dependent variable. The Pesaran test rejects the null of cross section dependence with $p=0.39$.
} 


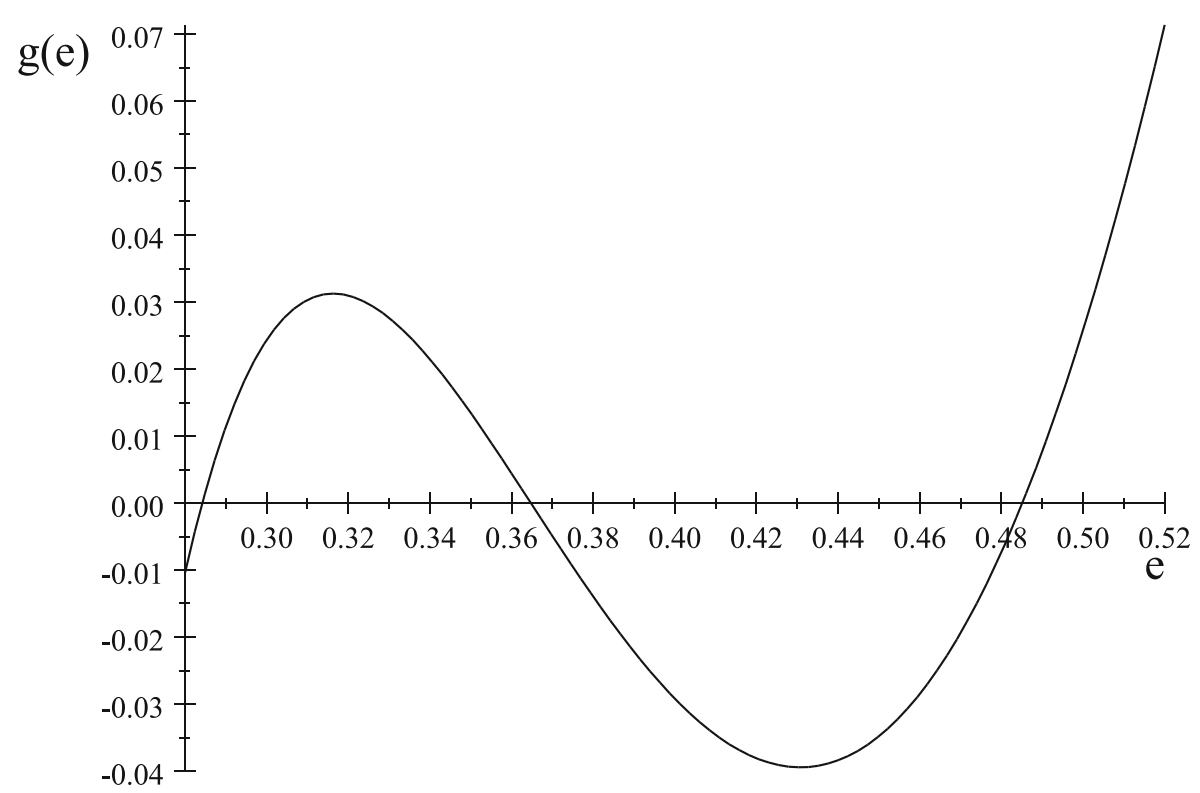

Fig. 1 Estimated dynamics of education time-share e

slightly below their maximum estimate. As in Lucas (1988) our version of the model implies passing on human capital over generations. In contrast, life-cycle and vintage models tend to assume that this is not the case and each generation starts with the same initial value (see for example Heijdra and Romp 2009a; Ludwig et al. (2012). This leads to different calibrations because higher human capital implies higher productivity, externalities and wages, which all affect the choice of time inputs. In particular, estimation of the rate of depreciation for human capital as being between 1 and $1.5 \%$ is based on estimates for workers using a method where the loss upon retirement is not included (Arrazola and de Hevia 2004); they are applied in models with exogenous growth. We fit the data to get an endogenous growth rate of $h$ to be $1.3 \%$; the depreciation rate of $3 \%$ preferred by Mankiw et al. (1992) produces this result. Table 1 collects the steady state values in under the assumption of a value of $5 \%$ for the interest term. Values for the solution of the model below are slightly different as the interest term then is endogenous. These values would imply a slightly negative growth rate of the dependency ratio: $1+g_{1+D} \equiv \frac{1+g_{N}}{1+g_{L}}=\frac{1.002}{1.0021}=0.9999$, which will be above unity when $e^{*}$ and $g_{L}$ are lower in Table 2 below.

The result of this calibration can also be interpreted as the limiting case of a country that is small in regard to the impact on the interest rate, $\eta_{r b}=0$, and has a world market interest rate of $r=0.05$. The transversality conditions hold under the current calibration (see appendix).

The above calibration analysis assumes a given product of interest rate and interest elasticity. This assumption will now be relaxed as it is unlikely to be fulfilled for most countries analyzed in the sample such as the US, Germany and France. They are too large to fit the assumption of being 'atomistically small', which is the exact version of being a price taker. In a risk-perception mark-up interpretation the assumption of 
endogenous interest rates is also valid at high debt levels of relatively small countries. Therefore, to analyze the dynamics and steady-state determination it is useful to assume a non-fixed interest rate, which depends on the debt of the country as we did in the dynamic optimization above. ${ }^{11}$ We use the estimate of Gaessler and Ziesemer (2016; Fig. 7):

$$
r\left(b_{t}\right)=0.815 \exp ^{-0.564 \log \left[2+b_{t}\right]^{2}+0.214 \log \left[2+b_{t}\right]^{3}}\left(2+b_{t}\right)^{0.605}(1+\bar{r})^{0.566}-1
$$

Where $\boldsymbol{b}_{\boldsymbol{t}}=\frac{\boldsymbol{B}_{t}}{\boldsymbol{Y}_{t}}$ and $\overline{\boldsymbol{r}}$ is the world interest rate, approximated by the US interest rate, which is on average 0.05 . The curve has an intercept at about $5 \%$ and then goes to 0.17 for $b=2$ with a steep slope for low debt ratios and a flatter one for higher debt ratios. The elasticity of the interest rate with respect to the debt to GDP ratio, $\boldsymbol{\eta}_{\boldsymbol{r}}$, is derived from Eq. (13) with $\boldsymbol{\eta}_{r b}=\boldsymbol{b}_{\boldsymbol{t}} \frac{\boldsymbol{r}^{\prime}\left(\boldsymbol{b}_{\boldsymbol{t}}\right)}{\boldsymbol{r}\left(\boldsymbol{b}_{\boldsymbol{t}}\right)}$ :

$$
\eta_{r b}=b_{t}\left(\frac{0.507 \exp p^{-0.564 \log \left[2+b_{t}\right]^{2}+0.214 \log \left[2+b_{t}\right]^{3}}}{\left(2+b_{t}\right)^{0.396}}+0.838\left(2+b_{t}\right)^{0.605} \exp ^{-0.564 \log \left[2 b_{t}\right]^{2}+0.214 \log \left[2+b_{b}\right]^{3}}\left(-\frac{1.127 \log \left[2+b_{t}\right]}{2+b_{t}}+\frac{0.642 \log \left[2+b_{t}\right]^{2}}{2+b_{t}}\right)\right)
$$

The budget constraint can be rearranged to

$$
B_{t+1}=N_{t} c_{t}+K_{t+1}-\left(1-\delta_{k}\right) K_{t}-Y_{t}+\left(1+r\left(\frac{B_{t}}{Y_{t}}\right)\right) B_{t}
$$

Expressing (14) in terms of $b_{t}=\frac{B_{t}}{Y_{t}}$ and setting $\frac{N_{t} c_{t}}{Y_{t}}=X_{t}$ it must hold (see Appendix) that

$$
\left(1+g_{b}\right)=\frac{1}{1+g_{Y}}\left(\frac{1}{b_{t}} X_{t^{-}}-\frac{1+\frac{1-\alpha}{r\left(b_{t}\right)\left(1+\eta_{r b}\right)+\delta_{k}}\left(\left(1-\delta_{k}\right)-\left(1+g_{Y}\right)\right)}{b_{t}}+\left(1+r\left(b_{t}\right)\right)\right)
$$

In steady state, $g_{b}=0$ and Eq. (15) solved for $X_{t}$ becomes

$$
X_{t}=\left(1+g_{Y}-\left(1+r\left(b_{t}\right)\right)\right) b_{t}+\frac{(1-\alpha)\left(1+g_{Y}\right)}{r\left(b_{t}\right)\left(1+\eta_{r b}\right)+\delta_{k}}\left(\frac{\left(1-\delta_{k}\right)}{1+g_{Y}}-1\right)+1
$$

The formula for the growth rate of output is (12c)'. For $\frac{N_{t} c_{t}}{Y_{t}}=X_{t}$ as the consumption share, $1+g_{X}$ is by definition and use of $(12 \mathrm{a})^{\mathrm{I}}$ and $(12 \mathrm{c})^{\mathrm{I}}$

$$
\begin{aligned}
1+g_{X} & =\frac{\left(1+g_{N}\right)\left(1+g_{c}\right)}{1+g_{Y}} \\
& =\frac{1+g_{N}}{\left(F e_{t}^{\gamma}+\left(1-\delta_{h}\right)\right)^{1+\frac{\epsilon}{\alpha}}\left(1+g_{L}\right)}\left[\beta\left(1+r\left(b_{t}\right)\left(1+\eta_{r b}\right)\right)\right]^{\frac{1}{\sigma}}
\end{aligned}
$$

\footnotetext{
${ }^{11}$ A fixed interest rate in the dynamic optimization may lead to infinite consumption through infinite borrowing. 
Where $1+g_{y}$ and $1+g_{c}$ are their respective steady state relations. In steady state $g_{X}=0$, with the expression for $r\left(b_{t}\right)$ of Eq (13), Eq. (16) becomes:

$$
\frac{1}{\beta}\left(\frac{\left(F e_{t}^{\gamma}+\left(1-\delta_{h}\right)\right)^{1+\frac{\epsilon}{\alpha}}\left(1+g_{L}\right)}{1+g_{N}}\right)^{\sigma}=\left(1+r\left(b_{t}\right)\left(1+\eta_{r b}\right)\right)
$$

With the steady state expression for $1+g_{L}$ of Eq. $(12 \mathrm{e})^{\mathrm{I}}$ Eq. $(16)^{\mathrm{I}}$ becomes

$$
\left(\left(F e_{t}^{\gamma}+\left(1-\delta_{h}\right)\right)^{\left(1+\frac{1}{\vartheta}\right)\left(1+\frac{\epsilon}{\alpha}\right)}\right)^{\sigma}=\beta^{1+\frac{\sigma}{\vartheta}}\left(1+r\left(b_{t}\right)\left(1+\eta_{r b}\left(b_{t}\right)\right)\right)^{1+\frac{\sigma}{\vartheta}}
$$

Equations $(12 \mathrm{~d})^{\mathrm{III}},(15)^{\mathrm{I}}$ and $(16)^{\mathrm{II}}$ form the dynamic system to determine education time share $e$, debt/GDP ratio $b$ and consumption share $X$. To illustrate the solution, Eq. $(15)^{\mathrm{I}}$ we plot in the $X-b$ plane in the left panel of Fig. 2 for a given $e$, which can be found from the intersection of Eqs. $(12 \mathrm{~d})^{\mathrm{III}}$ and $(16)^{\mathrm{II}}$ plotted in the right panel of Fig. 2 in the $e-b$ plane. Their intersection denotes the steady state $e^{*}=0.380$ and $b^{*}=0.038$. With these values, the steady-state consumption share, $X^{*}=0.694$, can be derived from Eq. (15) ${ }^{\mathrm{I}}$. We summarize this result as proposition 1.

Proposition 1: Our open economy model has a unique steady state in education time e, debt ratio $b$, and consumption share $X$ from which the growth rates of all other variables can be derived.

The formulas in Table 1 depend only on $e$ and $b$. The value for $e^{*}$ differs from the steady state value for a given interest rate of $5 \%$ in Table 1 , where $e^{*}=0.399$. This is due to a lower interest rate because of a lower debt through optimization exploiting the interest rate function. The interest rate associated with a value of $b^{*}=0.038$, according to (13), leads to $r\left(1+\eta_{r b}\right)=0.0496$, instead of $r\left(1+\eta_{r b}\right)=0.05$ (which we would get for $b=0.042$ ). The solution is $r=0.0468$ and $\eta_{r b}\left(b^{*}\right)=0.06$. A country that has an impact on the interest rate reduces credit at low levels to keep the interest rate low, here even below the average US value of $\bar{r}=0.05$. With these values, the growth rates of labour force growth changes to $1+g_{L}=1.0016$ (from 1.0021), leading to a growth rate of the dependency ratio of $1+g_{1+D}=1.00043$ (from 0.999922). This result is summarized in proposition 2.

Proposition 2: A small open economy with no influence on the interest rate will choose a higher growth rate of the active population, a lower growth rate of ageing, and a higher share of time devoted to education as opposed to an economy with a flexible interest rate, which is lower through lower of debt and growth.

Once there is the possibility to adjust the interest rate, the economy will reduce their time devoted to education and the growth rate of the share of the active population, $L_{t} t$ $N_{t}$. This will increase its inverse, the growth rate of the dependency ratio. With a lower interest rate through less borrowing, the marginal product of capital must be lower, the capital-labour ratio must be higher in spite of less debt, and this effect comes from using less active time $L$ in spite of a higher share of working time, because human capital is now less profitable. This is a comparison of models with different impact on the domestic or world market interest rate. This is important to understand, because ageing goes together with less education in this model comparison. 


\section{Changes in the population growth rate}

\subsection{Numerical evaluation and comparison with the literature}

This section exogenously alters the population growth rate to analyze the reactions of the economy if $g_{N}$ falls from 0.002 to 0.001 . The first value is close to what our sample of 14 countries currently has; the logic also holds for the fall from higher rates in the 1960s. The economy reacts to an exogenous change in the population growth rate by altering the steady state time spent in education. This in turn alters the growth rate of the active population, $\boldsymbol{g}_{L}$, and with it the growth rates of capital and output. Fig. 3 shows the movement of the $\boldsymbol{g}_{\boldsymbol{e}}=\mathbf{0}, \boldsymbol{g}_{\boldsymbol{b}}=\mathbf{0}$ and $\boldsymbol{g}_{\boldsymbol{X}}=\mathbf{0}$ curves if $\mathbf{g}_{\mathrm{N}}$ goes from $\mathbf{0 . 0 0 2}$ to 0.001. The solid lines in Fig. 3 are the same as the lines in Fig. 2 and are drawn for a population growth rate of 0.002 . The dashed lines in Fig. 3 show the relations for a lower population growth of 0.001 .

Equations (12d) $)^{\mathrm{III}}$ and (16) ${ }^{\mathrm{II}}$ are solved dependent on the population growth rates. Population growth therefore has an impact on education and via the debt/GDP ratio on the interest rate. The impact of population growth therefore goes through three channels. First, the effect on education goes through all formulas in Table 1. Second, the effect on the interest rate goes to labour supply and consumption growth. Third, population growth has a direct effect on labour supply growth in Table 1.

Table 2 shows the optimal response of some measures of the economy to an exogenously changing growth rate of population around zero, which we summarize in proposition 3 .

Proposition 3: In the open economy Lucas model with imperfect capital movements, a decrease (increase) in the current population growth rate leads to a decrease (increase) of labour and the dependency growth, the debt ratio, interest rates and the education time share.

In the middle of the 1960s, this was a strongly falling growth rate of the population, but most recently, it is a slightly increasing one because of old-age mortality reduction from post WWI vintages leaving the population. Column 3 shows the corresponding values of the growth rate of the dependency ratio. The growth rate of the active population does not change one-to-one with the growth rate of the total population. This means that the growth rate of the dependency ratio decreases (increases) with decreasing (increasing) population growth, because the growth rate of human capital, $h$, adjusts too. Mason et al. (2016) find this result in terms of levels of an increasing ratio $L / N$ in a modified Mankiw-Romer-Weil model. When current population growth decreases - which may have different effects from considering that of forty years ago (Maestas et al. 2016) -, the best response for education is a decrease in the time share devoted to education, ${ }^{12}$ leaving a larger time share in production. When interest rates fall due to a drop in population growth, education time also falls. By comparing the first two columns it becomes apparent, that the optimal response of the growth rate of the active population is always a bit less downward than the population growth rate. A similar relation between growth of the population and more education has been found

\footnotetext{
12 Bucci et al. (2018) find a positive correlation between education and population for a cross-section of countries, but beyond a population growth rate of about $2 \%$ it changes sign.
} 

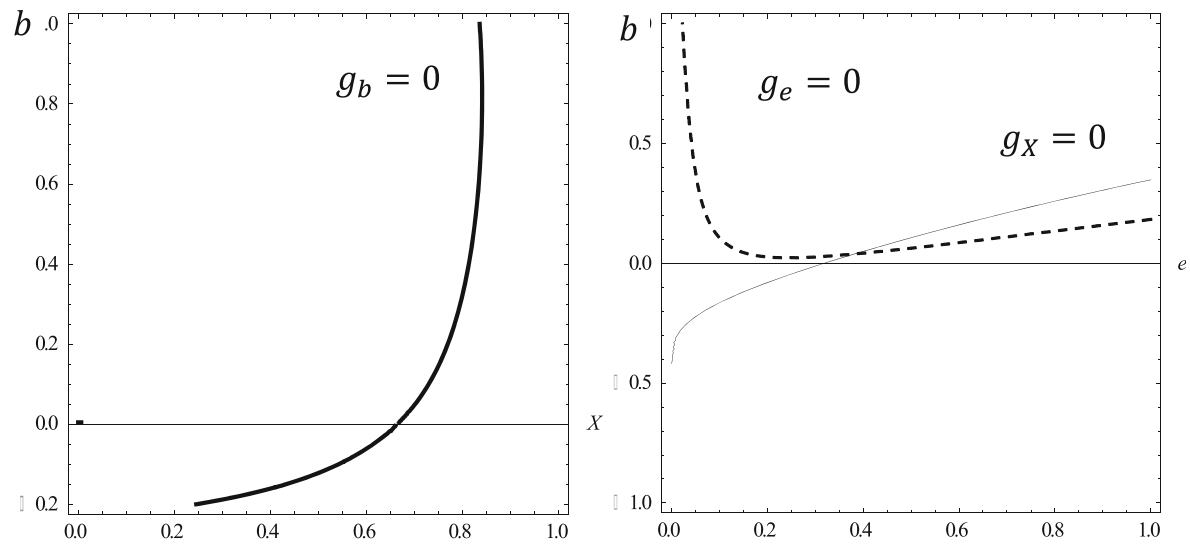

Fig. 2 - Steady states in $b_{t}, X_{t}$ and $e_{t}$

in the literature: In a model by de la Croix and Licandro (1999) life expectancy increases population growth and yields more education unless too many old agents stay in the labour force. Boucekkine et al. (2002) obtain the same result for a more realistic survival law inducing that the effect of too many old agents comes about only beyond age of 85; in Boucekkine et al. (2003) this latter effect is therefore not relevant when the model is calibrated to data for Geneva 1625-1825. The latter model assumes, unlike our version of the Lucas model, the old not to have the opportunity to invest time in education; and other ways to care for the old age like saving, borrowing, and a leisure-labour choice except for retirement are not considered. Therefore, it would not be obvious a priori whether more or less education is the optimal response to ageing in the Lucas model allowing for these aspects as it is in the pure growth-educationsurvival models. Heijdra and Romp (2008, 2009a), allowing for savings and borrowing at a given world market interest rate, find a positive effect of reduced adult mortality on education in a vintage model. In our version of the Lucas model education time, $e^{*}$, increases (decreases) if the growth rate of the dependency ratio increases (decreases) in

Table 1 Calibration for steady-state growth

\begin{tabular}{lll}
\hline Steady state relations & From Equation & Numerical \\
\hline $1+g_{h}=F e^{\gamma}+\left(1-\delta_{h}\right)$ & $(5)$ & $g_{h}=0.013$ \\
$1+g_{L}=\left(1+g_{N}\right)\left(1+g_{h}\right)^{\left(\frac{1}{\gamma}+\frac{\epsilon}{\gamma \alpha}\right)}\left(\frac{1}{\beta\left(1+r\left(\frac{B_{t}}{Y_{t}}\right)\left(1+\eta_{r b}\right)\right)}\right)^{\frac{1}{\gamma}}$ & $(12 \mathrm{e})^{\mathrm{I}}$ & $g_{L}=0.0021$ \\
$1+g_{Y}=\left(F e_{2}^{\gamma}+\left(1-\delta_{h}\right)\right)^{1+\frac{\epsilon}{\alpha}}\left(1+g_{L}\right)$ & $(3)$ and $(12 \mathrm{c})^{\mathrm{I}}$ & $g_{Y}=0.033$ \\
$1+g_{K}=\left(F e_{2}^{\gamma}+\left(1-\delta_{h}\right)\right)^{1+\frac{\epsilon}{\alpha}}\left(1+g_{L}\right)$ & $(12 \mathrm{c})^{\mathrm{I}}$ & $g_{K}=0.033$ \\
$1+g_{\omega}=\left(F e_{2}^{\gamma}+\left(1-\delta_{h}\right)\right)^{\frac{\epsilon}{\alpha}}$ & $(2)^{\mathrm{II}}$ & $g_{\omega}=0.018$ \\
$1+g_{\mu}=(\beta(1+r))^{-1}$ & $(9)$ & $g_{\mu}=-0.030$ \\
$1+g_{\mu_{h}}=\frac{1}{\beta\left(1+r\left(\frac{B_{t}}{Y_{t}}\right)\left(1+\eta_{k_{b}}\right)\right)}\left(F e_{2}^{\gamma}+\left(1-\delta_{h}\right)\right)^{\frac{\epsilon}{\alpha}}\left(1+g_{L}\right)$ & $(7)$ & $g_{\mu h}=-0.011$ \\
$1+g_{c}=\left[\beta\left(1+r\left(\frac{B_{t}}{Y_{t}}\right)\left(1+\eta_{r b}\right)\right)\right]^{\frac{1}{\sigma}}$ & $(6),(9),(12 \mathrm{a})^{\mathrm{I}}$ & $g_{c}=0.029$ \\
\hline
\end{tabular}

Note to table: In steady state: $\boldsymbol{g}_{\boldsymbol{e}}=\boldsymbol{g}_{\mathbf{1}-\boldsymbol{e}}=\mathbf{0}$ and $\boldsymbol{e}^{*}=\mathbf{0 . 3 9 9}$, parameter values are: $\overrightarrow{r\left(\frac{B_{t+1}}{Y_{t+1}}\right)\left(1+\eta_{r b}\right)=0.05}, \alpha=0.6, \delta_{h}=0.03, g_{N}=0.002, \quad F=0.055, \gamma=0.268, \epsilon=0.834, \sigma=1.06, \beta=0.982, \vartheta=3$. 
Table 2 Consequences of changes in the population growth rate

\begin{tabular}{lllllllllll}
\hline$g_{N}$ & $g_{L}$ & $10000 * g_{I+D}$ & $e_{t}$ & $b_{t}$ & $X_{t}$ & $r_{t}(1+\eta)$ & $1+g_{c}$ & $1+g_{h}$ & $\begin{array}{c}\left(1+g_{Y}\right) / \\
\left(1+g_{N}\right)\end{array}$ \\
\hline 0.002 & 0.00157 & 4.3 & 0.380 & 0.0383 & 0.694 & 0.0496 & 1.0287 & 1.0124 & 1.0295 \\
0.001 & 0.00059 & 4.1 & 0.366 & 0.0297 & 0.700 & 0.0484 & 1.0277 & 1.0120 & 1.0285 \\
0 & -0.0004 & 4.0 & 0.352 & 0.0216 & 0.706 & 0.0473 & 1.0267 & 1.0116 & 1.0275 \\
-0.001 & -0.00138 & 3.8 & 0.340 & 0.0137 & 0.713 & 0.0463 & 1.0257 & 1.0112 & 1.0265 \\
-0.002 & -0.00237 & 3.7 & 0.328 & 0.0062 & 0.720 & 0.0453 & 1.0248 & 1.0108 & 1.026 \\
\hline
\end{tabular}

reaction to increasing (decreasing) population growth rates as in Table 2 although labour-leisure choice leads to a higher growth of the dependency ratio under lower mortality and higher population growth. Decreasing (increasing) education $e^{*}$ implies less (more) growth of labour efficiency, $h_{t}$, which dominates the effects on the growth of production; moreover, there is less (more) capital inflow and lower (higher) interest rates. Combining (12f) with these values shows that the growth rate of the GDP per capita of the population moves together with the growth rate of the population (see second but last column in Table 2). The reason is that the change in the GDP growth rate via that of human capital is stronger than the change of the interest rate; the high inverse Peterman labour supply elasticity in (12f) mitigates both. Heer and Irmen (2014) find the opposite result: labour scarcity leads to higher growth. The reason for the difference is in the capital-intensity of the two models following the intuition of the Rybczynski effect. In the Lucas model the output production function is capitalintensive and the productivity function is labour-intensive. In Heer and Irmen (2014) the productivity function employs no labour and the output production function - after insertion of intermediates - employs labour and capital (see also their Lemma 1). In both models, in line with the Rybczynski effect, the labour-intensive sector shrinks, and the capital-intensive sector expands when growth rates of the population and the labour force fall. Our empirical evidence below and historical considerations (see Cervellati et al. 2017) would favour a positive long-term relation between growth rates of
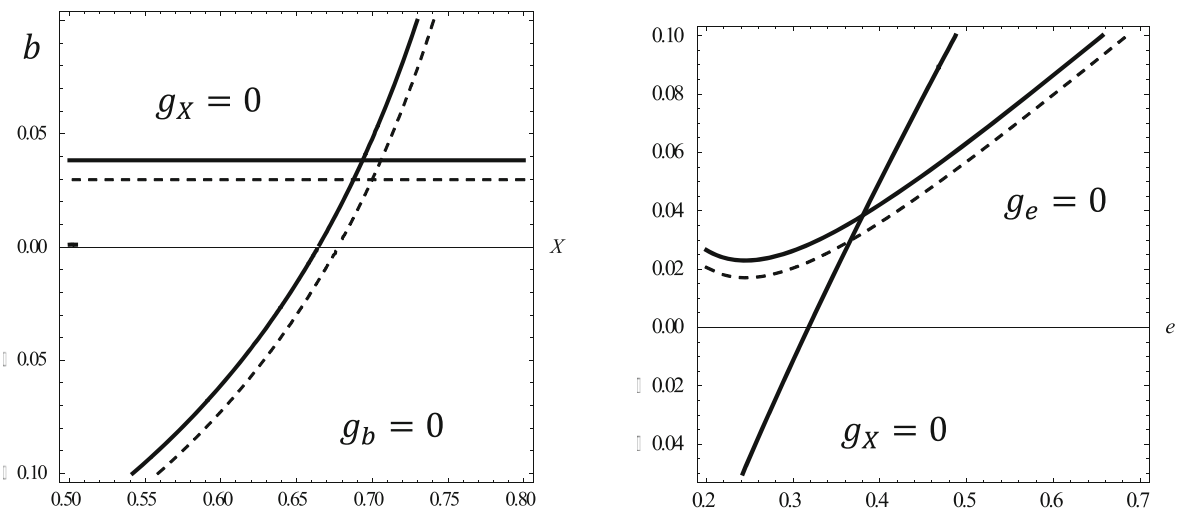

Fig. 3 Changes in the population growth rate. $\boldsymbol{g}_{N}=\mathbf{0 . 0 0 2}$ : solid lines, and $\boldsymbol{g}_{N}=\mathbf{0 . 0 0 1}$ : dashed lines 
population and per capita income. Which result is more realistic therefore depends on the capital-intensity ranking of knowledge and output production functions.

As in Mason et al. (2016) a fall in the growth rate of the population goes together with an increase in the efficient capital-labour ratio because the interest rate is falling and so is the marginal product of capital. The lower interest rate indicates that there is a lower debt/GDP ratio or, as Mason et al. (2016) put it, 'people accumulate more assets', but the capital-output ratio is constant in their model but increases in ours. Savings therefore must be higher in spite of lower interest rates. Investment in human capital per child is also increasing in their model. In the Lucas model, variables 'per child' are not explicitly visible, but instead we can express investment in education per head of the population as $e L / N$. It follows from Table 2 that the growth rate of $e L / N$ is also higher if population growth is lower, because $g_{e}=0$ and the growth rate of $L / N$ is increasing as $g_{1+D}$ is falling with $g_{N}$. So, in the interpretation and comparison of models, utmost care is in order in regard to the question, which human capital variable to use in interpretations. A fall in $e$ with a fall in $g_{N}$ is not contradicting the lessons Solow-Swan type of models used by Mason et al. (2016) as the growth of $e L / N$ goes up in our model because the growth of the share of active people goes up. However, although the growth rate of $L / N$ dominates in the long run, the initial change in levels also needs to be considered; we do this below.

\subsection{The demographic dividends in the Lucas model and recent history}

An important analytic step in the literature is to define and analyze the first and second dividend of falling population growth stemming from changes in $L / N$ and $Y / L$. Note though that the standard conventions about the dividend do not consider disutility from working. A higher $L / N$ is a blessing in the standard formulation on dividends, but it is dis-utility from the point of view of our model. Normally the dividends are expressed as a decomposition of consumption per capita and then terms from models are inserted. In our model, we have this in the form of Eq. (8), using (6) to replace the shadow price and (2) to replace the wage term. The result is

$$
c_{t}=\xi^{-\not \partial}\left(\frac{L_{t}}{N_{t}}\right)^{-y_{\sigma}}\left(\alpha \frac{Y_{t}}{L_{t}}\right)^{1 / \sigma}
$$

In terms of growth rates, from Table 2 for falling $g_{N}$ we get a fall in the growth rate of $c_{t}$, because the growth rate of $L / N$ is increasing and that of $Y / L$ is falling. Finding the growth rate for

$$
\frac{Y_{t}}{L_{t}}=\frac{\xi}{\alpha}\left(c_{t}\right)^{\sigma}\left(\frac{N_{t}}{L_{t}}\right)^{-\vartheta}
$$

is therefore a numerical problem for the growth rate version

$$
1+g_{y}=\left(1+g_{h}\right)^{1+\frac{\epsilon}{\alpha}}=\left(1+g_{c}\right)^{\sigma}\left(1+g_{1+D}\right)^{-\vartheta}
$$


The result from inserting parameter values from Table 1 and growth rates from Table 2 is that $g_{y}$ is falling with $g_{N}$ because $g_{h}$ is falling according to Table 2 as do $g_{c}$ and $g_{1+D}$. The last effect is the dynamic first dividend, which mitigates the fall of the growth rates because of the negative exponent. However, in models with dynamic optimization, falling (increasing) growth rates, which determine the levels of the future, go together with increasing (falling) initial current level values as is the case with the consumption share $X$ in Table 2. The standard decomposition (see Mason et al. 2016) in terms of our model is

$$
c=\frac{C}{N}=\frac{c N}{Y-r B} \frac{Y-r B}{(1-e) h L} \frac{(1-e) h L}{N}
$$

Dividing the numerator and denominator of the first two fractions by $Y$ we get

$$
\frac{C}{N}=\frac{c N / Y}{1-r b} \frac{1-r b}{(1-e) h L / Y} \frac{(1-e) h L}{N}
$$

Using $X=c N / Y$ and canceling $1-r b$ yields

$$
\frac{C}{N}=c=X \frac{Y}{(1-e) h L} \frac{(1-e) h L}{N}
$$

The dynamic version obtained above then can be re-phrased as follows. The left-hand side has a positive growth rate, which goes down though with $g_{N}$ according to Table 2 . The reason is that, together with the increase in $X$, the growth rate of $L / N$ increases (positive dynamic first future dividend) but less so than the growth rate of $Y / L$ falls (negative dynamic second future dividend with a positive static counter effect in the level of $X$ ). In terms of levels, $X$ is higher when $g_{N}$ is lower. $\frac{\boldsymbol{Y}}{(1-\boldsymbol{e}) \boldsymbol{h} \boldsymbol{L}}$ increases according to (1)-(3) when the interest rate falls. As $h$ is given initially and it has a lower but positive growth rate in the next period, the fraction has a higher level and therefore $\frac{\boldsymbol{Y}}{(\mathbf{1}-\boldsymbol{e}) \boldsymbol{L}}$ must be higher too in the first two periods. (1-e) is higher because $e$ is lower in Table 2. Thus, the straight line representing (17) in Fig. 4 has a higher slope when $g_{N}$ is lower. As $(1-e)$ is higher, $Y / L$ must be higher too; for the falling line in Fig. 4, representing $\left(8^{\prime}\right)$, this means that it shifts up and to the right. $C / N$ increases but the short-term effect on $L / N$ depends on the strength of the shifts. As in $\left(8^{\prime}\right) \sigma$ is close to one and both lines shift up with $Y / L$, the falling curve shifts up slightly less and the additional effects of $X$ and (1-e) in the upward sloping curve suggests that initial $L / N$ is lower, while the growth rate is larger, both for lower $g_{N}$. Proposition 4 summarizes the main result.

Proposition 4: A fall in the population growth rate has positive welfare effects in the short run through higher output per worker, consumption per capita, and lower labour per capita. Growth rates go the opposite way, lower for output per worker and consumption per worker, and higher for labour per worker.

Thus, in the early phase we have a negative first dividend through lower $L / N$ upon impact, which is a higher utility from leisure in our model, and a positive second 
dividend upon impact through higher $Y / L$. Under sufficiently high discounting the short-term effect dominates, and welfare increases as consumption, $C / N$, goes up and disutility from work goes down. However, if discounting is weak the lower growth rate of $C / N$ and the higher growth rate of $L / N$ reduce welfare. A numerical analysis is required to find the exact results for Fig. 4 and for welfare.

\section{$L / N$}

In the semi-endogenous growth model of Prettner and Trimborn (2017) initial and medium term consumption is lower instead, because their closed economy model does not allow for a quick increase in capital and in the medium run labour moves from output into R\&D as opposed to the long run where it does the opposite, both effects decreasing output. Instead, our model has immediately and permanently less labour in the human capital equation because the economy can jump into the steady state because of the international capital mobility. The different transitional properties of open and closed economy models therefore have an impact on the second demographic dividend.

One implication of a lower initial $L / N$ in connection with a lower $e^{*}$ from lower $g_{N}$ is that the initial value of $e L / N$, time spent in education per head of the population, is also going down first, before the higher growth rate of $L / N$ indicated above dominates. This is plausible because a lower population growth may come from a lower fertility, less children go to school, and relatively more people that are adult are present. In the short run, lower population growth therefore leads to lower investment in education. In response to that, in the long run, $e L / N$ grows through the choice of less leisure and more activity, which partly goes into education. This indicates that when the support ratio $L / N$ grows education time per head of the population also grows. Human capital, $h(t)$, though, has a lower growth rate right from the beginning and in the long run. An optimal choice of increasing labour supply over time therefore leads to a lower growth rate of the dependency ratio and less technical change after a fall in the population growth rate as it happened to occur in the early 1960s. Once education and endogenous growth play a role, the traditional result of ageing going together with capital outflow and lower interest (see Fehr et al. 2010, p.640) holds for higher initial levels of ageing measured by $N / L$ in Fig. 4. However, it does not hold not in terms of growth rates, which go down and lead to less growth of ageing and an optimal reaction of having a lower share of time in education, $e$, as can be seen from Table 2.

Under endogenous labour supply, lower population growth leads to more ageing in the short run and less in the long run, whereas under exogenous labour supply growth there is no counteracting effect in initial levels from optimization. This raises the question, whether labour supply was optimal in the past and will be chosen optimally in the future.

When population growth rates were falling before 1985, in particular in the 1950 and 1960s, those of labour supply also should have fallen, but this should have happened in a way that growth rates of dependency ratios should get lower as they do in Table 2 above. Indeed, this happened partly through increasing female labour participation. ${ }^{13}$ However, later misguided information regarding the level of pensions led to lower than optimal labour supply. The early implications are qualitatively those of Fig. 4, but sub-optimal. Once the mis-leading information has been corrected after

\footnotetext{
${ }^{13}$ See Bloom et al. (2009). Irmen (2018) reports an average fall of hours of US production workers of $0.0038 \%$ year. This value is larger than the absolute difference between the population and labour growth in our model. Female labour participation may be a major reason for this.
} 
the year 2000 the optimal labour supply model is more realistic. The later implications therefore are lower levels of consumption per capita because of lower growth rates of consumption and higher levels of $L / N$ because of higher growth rates of $L / N$. In regard to technical change this may imply that, among other factors, it was pushed upward when labour supply was growing slowly in the early phase of mis-leading pension information but is slowed down when labour supply grows more strongly now.

In our data set for 1985-2010, population growth has no significant trend in Austria, Finland, France, Sweden and the USA. Population growth rates are falling slightly in Canada, Germany, Greece and the Netherlands; the strongest negative trend for Germany is $\log (1+\mathrm{gN})=0.0051-0.000259 \mathrm{t}$, which is very small. Denmark, Spain, Ireland, Italy and the UK have slightly positive growth rates. The highest is in Ireland with $\log (1+\mathrm{gN})=-0.001785+0.000922 \mathrm{t}$. Overall, these rates are very small and can be considered as approximately constant as the left-hand side can be approximated by $g_{N}$ and one can find the number of years it takes to have the slope term at the order of magnitude of $1 \%$. Therefore, optimal and actual labour supply growth rates are approximately constant for this period ${ }^{14}$ and so are the growth rates of the dependency ratio $^{15}$ and education according to our model. No new changes of population growth have to be added to the earlier ones from the 1960s for our sample until 2010. For the whole OECD though there is a very recent increase in population growth through reduced mortality. ${ }^{16}$

Even if population growth would become negative, our model has a steady-state solution shown in Table 2 to which it can jump because of the international capital mobility. This is another major difference with the closed economy semi-endogenous growth model for which there is no steady state anymore, R\&D is given up successively and GDP per capita has a higher growth rate with more negative population growth rates (Sasaki and Hoshida 2017).

\section{Consequences of lack of past savings}

Because of early retirement in the 1980 s in response to low employment, less pension savings have been accumulated. The reason is that pension savings financed early retirement in connection with declining industries. Moreover, as demographic developments were visible already in the 1970s, people got the policy advice to save money privately as the European public pension systems would be insufficient to care for the old age phase. However, many people did not earn more than what is in some countries a minimum wage and could hardly save money privately. Finally, the middle classes, who saved money, and their semi-public pension funds were surprised by the recent phase of low interest rates, which stems partly from ample money supply and partly from the low population growth and high pension savings themselves. Our forwardlooking model captures this lack of cumulated savings only in the initial value of current wealth $W_{t}=K_{t}-B_{t}$. The marginal productivity condition for capital has a

\footnotetext{
${ }^{14}$ The Netherlands are the exception here with a statistically significant fall in $g_{L}$.

15 The exceptions here are the Netherlands and Ireland with a statistically significant increase in $g_{l+D}$.

${ }^{16}$ Lee and Mason (2010) analyse a series of combined changes of fertility and mortality rates.
} 


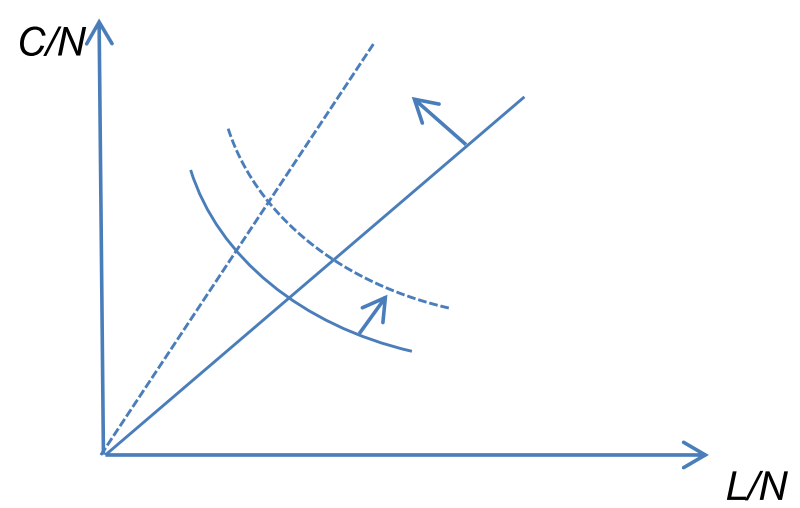

Fig. 4 Lower population growth leads to higher initial consumption per capita, and a lower initial activity ratio, whereas growth rates for both go the opposite direction

constant interest rate as soon as the solution for $b=B / Y$ is found. Therefore, the righthand side of the combination of $(12 b)$ and $(12 c)$ is also determined. This was already taken into account when deriving $(15)^{\mathrm{I}}$, on which the solution for $b$ is based. Constant $\frac{\boldsymbol{K}_{t+1}}{\boldsymbol{Y}_{t+1}}=\frac{1-\alpha}{r\left(\frac{B_{t+1}}{Y_{t+1}}\right)\left(\mathbf{1}+\eta_{r b}\right)+\delta_{k}}=\frac{W_{t+1}+\boldsymbol{B}_{t}}{\boldsymbol{Y}_{t+1}}$, indicates that a lower wealth/GDP ratio requires a higher debt/GDP ratio for a given interest rate and this is mitigated if the interest rate increases through a higher debt/GDP ratio because a higher marginal product of capital requires less capital. In other words, the solution of the model implies that countries with lower current wealth have higher debt and interest rates. The higher interest rate from more borrowing compensating lower current wealth would lead to a higher education value $e^{*}$. Higher education time therefore compensates for low past savings. In Fig. 3 the $g_{e}=0$ curve would be at higher values of $b$, leading to intersection points with the $g_{X}=0$ curve at higher values of $b^{*}$ and $e^{*}$. This in turn would lead to a higher position of the $g_{b}=0$ curve, leading to a lower current consumption share $\mathrm{X}^{*}$, which in turn is in line with a higher consumption growth rate following from a higher interest rate. Proposition 5 summarizes these results.

Proposition 5: Lower past savings imply higher values for the debt ratio, interest rate, education time, and growth rates of human capital, output per worker, wages, and consumption.

Shifting consumption forward is the price paid for a neglect of pension savings in the past and its compensation through higher education today. In other words, if ageing goes together with low accumulated savings, the interest rate will be higher, not lower. Moreover, this adds to the list of answers to the ageing problem - female labour participation, working more now or later through increasing retirement age (Bloom et al. 2010) - the suggestion of producing more endogenous growth as a second-best policy. ${ }^{17}$ From the perspective of convergence, the widespread view that in the Lucas model all countries have the same growth rate does not hold anymore with interest rates driven by foreign debt ratios. Lower wealth implies higher growth rates.

\footnotetext{
${ }^{17}$ Households take the impact on the interest rate into account, but not the human-capital externality in the output-production function.
} 
Table 3 Model solutions for alternative Frisch parameters

\begin{tabular}{rllllllll}
\hline vartheta & $g_{N}$ & $e$ & $b$ & $r$ & $\eta$ & $1+r(1+\eta)$ & $1+g_{h}$ & $1+g_{L}$ \\
\hline 0.33 & 0.002 & 0.38397 & 0.038778 & 0.047057 & 0.054214 & 1.049608 & 1.012555 & 1.000688 \\
0.5 & 0.002 & 0.38395 & 0.039988 & 0.047137 & 0.055728 & 1.049763 & 1.012555 & 1.000835 \\
0.8 & 0.002 & 0.38387 & 0.041549 & 0.047239 & 0.057666 & 1.049963 & 1.012552 & 1.001027 \\
1 & 0.002 & 0.38381 & 0.042331 & 0.047290 & 0.058631 & 1.050063 & 1.012551 & 1.001122 \\
1.33 & 0.002 & 0.38373 & 0.043330 & 0.047356 & 0.059858 & 1.050190 & 1.012548 & 1.001244 \\
8 & 0.002 & 0.38331 & 0.047916 & 0.047655 & 0.065408 & 1.050772 & 1.012536 & 1.001801 \\
vartheta & $g_{N}$ & $1+g_{Y}$ & $X$ & $1+g_{c}$ & $1+g_{w}$ & $1+g_{(l+D)}$ & $1+g_{Y} / 1+g_{N}$ & $1+g_{N}$ opt \\
0.33 & 0.002 & 1.030978 & 0.692983 & 1.028952 & 1.017495 & 1.001311 & 1.028921 & 1.001117 \\
0.5 & 0.002 & 1.031129 & 0.69281 & 1.029095 & 1.017494 & 1.001164 & 1.02907 & 1.001266 \\
0.8 & 0.002 & 1.03132 & 0.692596 & 1.02928 & 1.01749 & 1.000972 & 1.029262 & 1.00146 \\
1 & 0.002 & 1.031414 & 0.6925 & 1.029372 & 1.017488 & 1.000877 & 1.029355 & 1.001557 \\
1.33 & 0.002 & 1.031534 & 0.692374 & 1.02949 & 1.017485 & 1.000755 & 1.029475 & 1.001681 \\
8 & 0.002 & 1.032078 & 0.691831 & 1.030028 & 1.017467 & 1.000198 & 1.030018 & 1.002246 \\
\hline
\end{tabular}

Table 4 Model solutions for alternative rates of human capital depreciation

\begin{tabular}{rlllllll}
\hline depr & $\mathrm{g}_{\mathrm{N}}$ & $\mathrm{e}$ & $\mathrm{b}$ & $\mathrm{r}$ & $\eta$ & $1+\mathrm{r}(1+\eta)$ & $1+\mathrm{g}_{\mathrm{h}}$ \\
\hline 0.02 & 0.002 & 0.361 & 0.271 & 0.061 & 0.235 & 1.075 & 1.022 \\
0.03 & 0.002 & 0.384 & 0.046 & 0.048 & 0.063 & 1.051 & 1.013 \\
0.033 & 0.002 & 0.391 & -0.008 & 0.044 & -0.013 & 1.043 & 1.010 \\
0.034 & 0.002 & 0.393 & -0.025 & 0.043 & -0.042 & 1.041 & 1.009 \\
0.035 & 0.002 & 0.396 & -0.041 & 0.042 & -0.072 & 1.039 & 1.008 \\
0.036 & 0.002 & 0.398 & -0.057 & 0.040 & -0.105 & 1.036 & 1.007 \\
0.037 & 0.002 & 0.401 & -0.072 & 0.039 & -0.140 & 1.034 & 1.006 \\
0.038 & 0.002 & 0.403 & -0.086 & 0.038 & -0.177 & 1.031 & 1.005 \\
0.04 & 0.002 & 0.408 & -0.114 & 0.036 & -0.259 & 1.027 & 1.003 \\
0.07 & 0.002 & 0.495 & -0.383 & 0.008 & -6.371 & 0.957 & 0.976 \\
depr & $1+\mathrm{g}_{\mathrm{L}}$ & $1+\mathrm{g}_{\mathrm{Y}}$ & $\mathrm{X}$ & $1+\mathrm{g}_{\mathrm{c}}$ & $1+\mathrm{g}_{\mathrm{W}}$ & $1+\mathrm{g}_{(1+\mathrm{D})}$ & $\left(1+\mathrm{g}_{\mathrm{Y}}\right) /\left(1+\mathrm{g}_{\mathrm{N}}\right)$ \\
0.02 & 1.00123 & 1.054 & 0.685 & 1.052 & 1.031 & 1.00076 & 1.052 \\
0.03 & 1.00156 & 1.032 & 0.692 & 1.030 & 1.017 & 1.00044 & 1.030 \\
0.033 & 1.00166 & 1.025 & 0.695 & 1.023 & 1.014 & 1.00034 & 1.023 \\
0.034 & 1.00169 & 1.023 & 0.696 & 1.021 & 1.012 & 1.00031 & 1.021 \\
0.035 & 1.00172 & 1.021 & 0.698 & 1.019 & 1.011 & 1.00028 & 1.019 \\
0.036 & 1.00175 & 1.019 & 0.699 & 1.016 & 1.010 & 1.00025 & 1.016 \\
0.037 & 1.00179 & 1.016 & 0.700 & 1.014 & 1.008 & 1.00021 & 1.014 \\
0.038 & 1.00182 & 1.014 & 0.702 & 1.012 & 1.007 & 1.00018 & 1.012 \\
0.04 & 1.00189 & 1.010 & 0.705 & 1.008 & 1.005 & 1.00011 & 1.008 \\
0.07 & 1.00288 & 0.945 & 0.800 & 0.943 & 0.966 & 0.99913 & 0.943 \\
\hline & & & & & & &
\end{tabular}


Whereas for any population level $N$ that may have been caused by low population growth in the past an optimal labour supply can be chosen to correct sub-optimal supply in previous periods, the effect of lower own capital and a higher interest rate is permanent for the country in question.

\section{Ageing in the Frisch parameter and depreciation of human capital}

One problem of ageing may come from a stronger dis-utility from work as workers get older. We assume that the Frisch parameter would get larger in an ageing society. The crucial point is how strongly elderly react to wage increases. Equation (8) tells us that the labour supply elasticity in reaction to wages is $1 / \vartheta$. If elderly react more hesitantly to wage offers, a higher Frisch parameter $\vartheta$ can capture this for those who are still working and a lower one for those who return from retirement.

For alternative Frisch parameters, the model has different solutions, of course. In Table 3, the Frisch parameter of 0.33 corresponds to Peterman's (2016) high Frisch elasticity of three. The Frisch parameter of 0.5 corresponds to Peterman's (2016) low Frisch elasticity of two. The Frisch parameter of 0.8 corresponds to Wallenius' (2011) Frisch elasticity of 1.25 . The Frisch parameter of unity corresponds to Malik (2013) with Frisch elasticity of unity. The Frisch parameter of 1.33 corresponds to a Frisch elasticity of 0.75 in Chetty et al. (2011).

The effects of moving from one Frisch parameter to another on all variables are in the order of magnitude of a tenth or hundredths of a percent with the exception of the debt ratio and the interest elasticity. ${ }^{18}$ Therefore, this is quantitatively of limited importance for the near future of the ageing problem and not discussed in detail. However, as Irmen (2018), our growth model captures the historical fall in labour per head of the population. It would stop only if the Frisch parameter goes to infinity. We approximate this by a parameter value of eight, leading to a supply elasticity of 0.125 .

Employers are very much afraid of losing high-skill workers through retirement. This, and morbidity effects emphasized by Aísa et al. (2012), can be captured by a larger rate of depreciation of human capital. However, in three-period models this is not possible in an empirically realistic way because human capital is built in the first period, used in the second, and depreciation by $100 \%$ occurs at the end of the second period. In our model, a higher rate of depreciation, say, from $3 \%$ to $3.3 \%$, decreases the yearly growth rate per worker by 0.007 percentage points. Table 4 shows that increasing rates of human capital depreciation lead to increasing time spent in education, as well as decreasing foreign debt ratios and interest rates, an effect missed out under the assumption of a given interest rate made in some papers as discussed above. Proposition 6 summarizes our result.

Proposition 6: The net effect of higher depreciation rates for human capital and more time in education is less growth of human capital, ${ }^{19}$ and more growth of labour time. The dependency ratio has a lower growth rate, and also wages, GDP per capita or per

\footnotetext{
${ }^{18}$ Gómez (2017) investigates the impact of the constant elasticity of factor substitution on the growth rates.

${ }^{19}$ Fertig et al. (2009) find a similar result in a regression for the age group 18-21.
} 
worker, and consumption per capita have a lower growth rate. Debt ratios decrease with higher depreciation and increase with lower labour supply elasticity.

More education and more labour supply growth mitigate the problem, but do not overcome it. In the estimates of Maestas et al. (2016,) a similar result is obtained by an increase of the share of the population above age 60 by $2 \%$. Moreover, the authors estimate that for the period 1980-2010 the yearly growth rate of the GDP per capita of the population in US states was $0.3 \%$ lower through ageing than without and $9.2 \%$ for the whole 30-year period. We get a similar result in Table 4 if the human capital depreciation rate increases by 1.5 tenths of a percent, say from 0.033 to $0.0345 \%$. Our model can obtain their expected growth rate of $0.7 \%$ for $2010-2020$ and $1.3 \%$ for 2020-2030 roughly by depreciation rates of 0.04 and 0.038 respectively. In our model, the growth of labour supply responds positively and therefore contributes in a mitigating way. The growth rate of the dependency ratio then falls to zero and gets negative if depreciation goes beyond 0.04 . The labour growth rate then gets higher than that of the population for the period of a high depreciation rate. For the period of ageing, households postpone their drift to more leisure according to our analysis.

Acemoglu and Restrepo (2017) show that there is no negative impact of the share of workers above age 50 on the growth of GDP per capita in a cross section of OECD countries, although Jones (2010) argues that great innovations are made at the age of the early forties. However, Aksoy et al. (2016), emphasizing that the most innovative age bracket is that 40-49, suggest a fall in the GDP growth rate through demographic changes within ten years for Sweden by $0.39 \%$, by $0.92 \%$ for the USA and $0.99 \%$ for Japan, and $1.12 \%$ for Canada. They provide a panel VAR analysis using employment data for eight ten-year age groups. Our model can generate all actual growth rates for the period 2000-2009 and growth rates calculated by the authors for the period 20102019 for 23 OECD countries through assumptions on the rate of depreciation for human capital between 0.02 and 0.07 . However, the period of ten years suggested by them may be a bit too short to get such a drastic fall. Our model includes one reaction of the economy in response to the problem, which Aksoy et al. (2016) do not include in their empirical model, which is the increase in the time-share for education increasing the endogenous technical progress. In addition, we include two variables, which they do not include in their theoretical model, leisure and foreign debt with an impact on the interest rate, which both help adjusting to the ageing problem or affecting the time length until it happens to occur. Finally, the age of great inventions may keep going upward and the age bracket for highest productivities may shift.

Choi and Shin (2015) find a fall in productivity through ageing only if inherited human capital is an average weighted with the strength of the vintages but not without weights. Older vintages have a higher share in the aggregation of human capital across vintages under conditions of ageing. The reason for a positive effect of ageing on growth under unweighted averaging is twofold. (i) They have an elasticity of only 0.1 where we have 0.267 for time in human capital formation; (ii) they have depreciation rates comparable to our formulas of 5 to $23 \%$ from young to old vintages, leading to almost no human capital near retirement age. However, in technologically advanced countries employers worry about their retirement and appreciate the skills of their older workers, which is at variance with the assumption of high depreciation rates. A higher rate of depreciation through ageing then has a stronger effect in our model than a shift to older generations in theirs. The authors correctly emphasize that the way of 
modelling the intergenerational transmission mechanism is important. However, our effort to calibration using the empirical work leading to Fig. 1 leads to more realistic numbers of $\gamma=0.267$ and a depreciation rate of 0.03 as in Mankiw et al. (1992). Ageing with positive growth effects seems to be unrealistic also for simple weighting schemes. Other differences between their model and ours are as follows. Interest rates fall more, and wages increase more under a closed economy assumption in their model because capital does not move out as it does in ours. As in our model, increased education time works against the consequences of ageing, but the higher interest rate in our model encourages education more than under autarky, although the effect of a higher rate of depreciation through ageing remains dominating.

In sum, it seems that of all effects of ageing considered in this paper, human capital loss through retirement captured by human capital depreciation has the strongest and most plausible effects in terms of relevant ranges for education time $e$, debt ratio $b$, and consumption share $X$ in Tables 2-4, in line also with other recent studies. Ludwig et al. (2012) have shown that human capital adjustment is an important mechanism reducing the welfare loss. In our case, each generation transfers human capital to the next and therefore the growth rate reduction through higher depreciation is much larger than in life-cycle models. In addition, foreign capital flows out and reinforces the effect.

Unlike these papers, our modelling strategy has de-emphasized the role of age brackets. Firms can shift tasks to younger and older persons when scarcity comes up. ${ }^{20}$ The loss of human capital, used as an indicator of ageing here, is not tied to rigid specifications of age brackets and not only to innovation but rather to productivity and its growth of the whole production.

In regard to the reaction of the savings or consumption ratios to ageing in the three forms considered in Tables 2-4 there is no clear result here as both are endogenous in the form of the consumption ratio $X$ and the growth rate of dependency ratio $g_{1+D}$. The relation depends on the exogenous change under consideration. When we vary population growth in Table 2, a higher growth rate of the dependency ratio leads to a higher savings ratio. If we change the Frisch parameter in Table 3, a higher growth rate of dependency leads to a higher consumption ratio. If we vary the depreciation rate in Table 4, a higher growth rate of dependency leads to a higher savings ratio. As the effects of the Frisch parameter are very small it follows that savings decrease with ageing at the moment of increasing depreciation of human capital. Once this phase is over and depreciation rates go back to former values savings rates will go up again.

A similar result exists for interest rates: with falling population growth and increasing human capital depreciation, interest rates are decreasing, but with increasing Frisch parameters, they are increasing. If the increase of depreciation rates is most important while population growth rates have become stable in the OECD and changing Frisch elasticities have hardly any effect here, then second-best optimal interest rates are going to fall according to our model. It puts stronger emphasis on the effect of growth on international capital movements in interest rate determination than the closed economy reasoning of several papers in the literature and therefore the effect of 'demographic trends on real interest rates'(Aksoy et al. 2017) may become a bit less of a puzzle.

\footnotetext{
${ }^{20}$ Industrial robots can probably take over some tasks (Acemoglu and Restrepo 2017). However, there timing perspective for robots focusses on 2025 whereas that of retirements focusses usually on 2040.
} 


\section{Summary, conclusion and suggestions for further research}

We extend the open economy version of the Uzawa-Lucas endogenous growth model allowing for imperfect capital movements, human capital depreciation, and endogenous labour supply.

We find a unique steady state when estimated debt-dependent interest rates are endogenous.

A decrease in population growth as it happened to occur in the OECD countries in the early 1960s leads to a lower dependency growth rate and time-share of active people in education but an increase in the growth rate of the education time per head of the population.

The dividends from lower population growth go in opposite directions in the short and the long run with per capita welfare increasing in the short run, through lower labour supply and more consumption, and decreasing in the long run because the growth rates go into the opposite direction than the early level effects.

Less growth leads to less debt, lower interest rates and higher consumption shares.

Moreover, a lower wealth/GDP ratio due to early retirement and lower pension savings in the past lead to higher interest rates and optimal education and growth rates, and shifts consumption into the future.

Central arguments in the public debate are increases in the retirement age and other alternatives of using more labour from reserves like unemployment, part time work and female labour participation. We have subsumed all these arguments under the labour supply variable. Making them explicit would require modelling many heterogeneous households - female/male, part-time/fulltime, employed/unemployed - and each of these phenomena could be caused either by the demand side or the supply side of the labour market or both. By implication, we would need many differently modelled households supplying labour. This can be a strong increase in costs for the researcher and for the readers. It is questionable whether the additional insights can justify the costs from this more detailed modelling. The business press estimates the effects of these labour market reserves to be not more than $20 \%$ of the labour force or $10 \%$ of the population while the problem is that of ageing turning a situation of two active workers per one retired into the opposite, one active worker per two retired. For the time being we think, that analysis of endogenous labour supply in its aggregated form is sufficient, because the need to retire later is uncontroversial in science. This is different in politics, where Germany and the Netherlands go to retirement at age 67 whereas France and Austria struggle about staying below an actual value of currently age 60 although Austria has decided to go to 67 . The major policy task here is to provide people with good information about expected pensions and remove lifetime discrimination from the current European retirement rules. If this is done, the attitudes towards working can be captured by the Frisch parameter in the standard labour supply model. The effect of varying Frisch parameters has been shown above to be very limited though. It cannot be the root cause of an increase or fall in labour supply except for very long periods. In times of a falling share of prime-aged married male household heads (Peterman 2016) may lead to time-varying Frisch parameters as an issue for further research; if they go to infinity or it's inverse to zero, this would lead to a constant labour/population ratio.

What matters mostly is the depreciation of human capital when ageing enhances it. This has a strong effect on growth in our model and the optimal policy is to increase the growth 
rate of overall labour supply and incur the cost of putting more labour into education. ${ }^{21}$ This reduces the growth rate of the dependency ratio. The increase in labour supply growth will not only come from reserves but also from full-time workers working more hours in response to increasing wages. This in turn will lead to a lower growth rate of wages. As the growth rate of GDP per capita will fall, the welfare cost of ageing are likely to be higher than in models with exogenous productivity growth (see Ludwig et al. 2012).

Going from human capital models to R\&D models would not change much, because labour (and capital in a lab-equipment model; Rivera-Batiz and Romer 1991) then would produce a growth rate of the number of intermediates rather than human capital, both of which represent technical change in their respective model class. In semi-endogenous growth models, there is most likely a similar impact of reductions in population growth on the longrun growth rate as shown by Prettner and Trimborn (2017). ${ }^{22}$ Including human capital makes these models similar to the Lucas model used here (Strulik 2005). Neither fully nor semiendogenous growth models should be ruled out according to the current state of evidence.

Another candidate for changing results or making them richer is the introduction of population vintages and cohort specific survival laws as in Boucekkine et al. (2002) or in Cervellati and Sunde (2013), who use survival laws with two and three parameters respectively. This would allow analyzing the effect of population changes per vintage stemming from earlier years. However, variations in death rates are small for years that are more recent. The implied loss of human capital discussed above seems to be more important.

Finally, endogenous growth rates of the population through endogenous fertility in connection with labour supply and growth, both endogenous, would lead to a differential equation in fertility. Simulations can then treat fertility shocks as of fifty years ago. We will consider doing this in future research.

It is clear though that all such modelling efforts would have to go through the same steps we have done: adjust the models, find a good calibration, also with the help of estimations when parameters are not readily available from the literature. Then, solving these models will again have to deal with non-linearities, at least where linearization can distort the results. We hope that our contribution helps making progress in this direction.

\section{Appendix: Transversality conditions}

The growth rate of $\beta^{t} \mu_{t} K_{t}$ and $\beta^{t} \mu_{h t} h_{t}$ must be negative for the transversality conditions to hold. With $\beta=0.982$, the growth rate of $\beta^{t}$ is -0.018 . With $g_{\mu}=-0.030$ and $g_{K}=$ 0.033 , the growth rate of the first transversality term is negative. The growth rate of the second transversality term is also negative because $g_{\mu h}=-0.011$ and $g_{h}=0.013$. The transversality conditions hence hold under the chosen calibration. The growth rate of the discount rate dominates that of the other two growth rates, which are almost equal. As $K$ and $B$ both have a constant ratio with output, they also have a constant ratio with each other. Transversality conditions for $B$ or for $K-B$ are therefore redundant.

\footnotetext{
${ }^{21}$ Romer (2001) discusses this type of policy for the USA in great detail. Heijdra and Romp (2009b) discuss taxation issues that could increase or reduce retirement.

${ }^{22}$ See also Prettner and Prskawetz (2010) on policy ideas in endogenous growth models, which are sometimes parameter shifts, which are costless by assumption.
} 


\section{Appendix: Derivation of the consumption share}

Equation (14) is the equivalent to Eq. (4) with $\omega_{t}$ and $r_{K t}$ at their equilibrium values shown in Eqs. (2) and (3) and, hence, with $\omega_{t}\left(1-e_{t}\right) h_{t} L_{t}+r_{k t} K_{t}=Y_{t} . K_{t+1}$ and $K_{t}$ can be replaced by $K_{t+1}=\frac{1-\alpha}{r\left(\frac{B_{t+1}}{Y_{t+1}}\right)\left(1+\eta_{r b}\right)+\delta_{k}} Y_{t+1}$ from Eqs. (12c) and (12b) with $R_{H t+1}$ $=R_{B t+1}=1+r\left(\frac{B_{t+1}}{Y_{t+1}}\right)\left(1+\eta_{r b}\right)$ for their respective periods. Expressing (14) in terms of $b_{t}=\frac{B_{t}}{Y_{t}}$ yields:

$$
b_{t+1}=\frac{N_{t} c_{t}}{Y_{t+1}}-\frac{\theta}{1+g_{Y}}+\frac{1+r\left(b_{t}\right)}{1+g_{Y}} b_{t}
$$

Where $\theta=\left(1-\delta_{k}\right) \frac{1-\alpha}{r\left(b_{t}\right)\left(1+\eta_{r b}\right)+\delta_{k}}+1-\left(1+g_{Y}\right) \frac{1-\alpha}{r\left(b_{t}\right)\left(1+\eta_{r b}\right)+\delta_{k}}$ and $b_{t}$ is constant in steady state. Setting $\frac{N_{t} c_{t}}{Y_{t}}=X_{t}$ in Eq. (14) $)^{\mathrm{I}}$ it must hold that

$$
\left(1+g_{b}\right)=\frac{1}{1+g_{Y}}\left(\frac{1}{b_{t}} X_{t}-\frac{1+\frac{1-\alpha}{r\left(b_{t}\right)\left(1+\eta_{r b}\right)+\delta_{k}}\left(\left(1-\delta_{k}\right)-\left(1+g_{Y}\right)\right)}{b_{t}}+\left(1+r\left(b_{t}\right)\right)\right)
$$

Solving for $X_{t}$ at constant $b_{t}$ yields the consumption share of Eq. (15) .

Open Access This article is licensed under a Creative Commons Attribution 4.0 International License, which permits use, sharing, adaptation, distribution and reproduction in any medium or format, as long as you give appropriate credit to the original author(s) and the source, provide a link to the Creative Commons licence, and indicate if changes were made. The images or other third party material in this article are included in the article's Creative Commons licence, unless indicated otherwise in a credit line to the material. If material is not included in the article's Creative Commons licence and your intended use is not permitted by statutory regulation or exceeds the permitted use, you will need to obtain permission directly from the copyright holder. To view a copy of this licence, visit http://creativecommons.org/licenses/by/4.0/.

\section{References}

Acemoglu D, Restrepo P (2017) Secular stagnation? The effect of aging on economic growth in the age of automation. MIT WP 12536, January 12. Short Version American Economic Review 107:174-179

Aísa R, Pueyo F, Sanso M (2012) Life expectancy and labour supply of the elderly. Journal of Population Economics 25:545-568

Aksoy Y, Basso HS, Smith RP, Grasl T (2016) Demographic structure and macroeconomic trends, BWPEF 1501, February

Aksoy Y, Basso HS, Smith RP (2017) Medium-run implications of changing demographic structures for the MACRO-economy. National Institute Economic Review 241:R58-R64

Arrazola M, de Hevia J (2004) More on the estimation of the human capital depreciation rate. Applied Economics Letters 11:145-148

Attanasio O, Kitao S, Violante GL (2007) Global demographic trends and social security reform. Journal of Monetary Economics 54:144-198

Bloom DE, Canning D, Fink G, Finlay JE (2009) Fertility, female labour force participation, and the demographic dividend. Journal of Economic Growth 14:79-101 
Bloom DE, Canning D, Fink G (2010) Implications of population ageing for economic growth. Oxford Review of Economic Policy 26:583-612

Bonneuil N, Boucekkine R (2017) Longevity, age-structure, and optimal schooling. Journal of Economic Behavior and Organization 136:63-75

Börsch-Supan A, Ludwig A, Winter J (2006) Ageing, pension reform and capital flows: a multi-country simulation model. Economica 73:625-658

Boucekkine R, De la Croix D, Licandro O (2002) Vintage human capital, demographic trends, and endogenous growth. Journal of Economic Theory 104:340-375

Boucekkine R, de la Croix D, Licandro O (2003) Early mortality declines at the Dawn of modern growth. The Scandinavian Journal of Economics 105:401-418

Boucekkine R, Martínez B, Ruiz-Tamarit JR (2013) Growth vs. level effect of population change on economic development: an inspection into human-capital-related mechanisms. Journal of Mathematical Economics 49: 312-334

Bowlus AJ, Mori H, Robinson C (2016) Ageing and the skill portfolio: evidence from job based skill measures. The Journal of the Economics of Ageing 7:89-103

Bucci A, Eraydın L, Müller M (2018) Dilution effects, population growth and economic growth under human capital accumulation and endogenous technological change. Working paper series in economics, Karlsruher Institut für Technologie (KIT), No. 113

Bun MJG, Windmeijer F (2010) The weak instrument problem of the system GMM estimator in dynamic panel data models. The Econometrics Journal 13:95-126

Cervellati M, Sunde U (2005) Human capital formation, life expectancy, and the process of development. The American Economic Review 95:1653-1672

Cervellati M, Sunde U (2013) Life expectancy, schooling, and lifetime labour supply: theory and evidence revisited. Econometrica 81:2055-2086

Cervellati M, Sunde U (2015) The economic and demographic transition, mortality, and comparative development. American Economic Journal: Macroeconomics 7:189-225

Cervellati M, Sunde U, Zimmermann KF (2017) Demographic dynamics and long-run development: insights for the secular stagnation debate. Journal of Population Economics 30:401-432

Chetty R, Guren A, Manoli D, Weber A (2011) Are micro and Macro labour supply Elasticities consistent? A Review of evidence on the intensive and extensive margins. American Economic Review: Papers and Proceedings 101:471-475

Choi K-H, Shin S (2015) Population aging, economic growth, and the social transmission of human capital: an analysis with an overlapping generations model. Economic Modelling 50:138-147

De la Croix D, Licandro O (1999) Life expectancy and endogenous growth. Economics Letters 65:255-263

de la Fuente A, Doménech R (2006) Human capital in growth regressions: how much difference does data quality make? Journal of the European Economic Association 4:1-36

Einarsson T, Marquis MH (1996) Note on human capital externalities. Journal of Macroeconomics 18:341-351

Fehr H, Jokisch S, Kotlikoff LJ (2010) Global growth, ageing, and inequality across and within generations. Oxford Review of Economic Policy 26:636-654

Fertig M, Schmidt CM, Sinning MG (2009) The impact of demographic change on human capital accumulation. Labour Economics 16:659-668

Frenkel JA, Razin A, Yuen C-W (1996) Fiscal policies and growth in the world economy. The MIT Press, Cambridge

Gómez MA (2017) Factor substitution and long-run growth in the Lucas model with elastic labour supply. Economics Letters 159:180-184

Gruescu S (2006) Population ageing and economic growth: education policy and family policy in a model of endogenous growth, vol 1431 Physica-Verlag Heidelberg

Ha J, Howitt P (2007) Accounting for trends in productivity and R\&D: a Schumpeterian critique of semiendogenous growth theory. Journal of Money, Credit and Banking 39:734-774

Heer B, Irmen A (2014) Population, pensions, and endogenous economic growth. Journal of Economic Dynamics \& Control 46:50-72

BJ Heijdra, WE Romp (2008) Human capital formation and macroeconomic performance in an ageing small open economy: further results. Supplement to Heijdra, ben J. and Ward E.Romp (2009a)

Heijdra B, Romp WE (2009a) Human capital formation and macroeconomic performance in an ageing small open economy. Journal of Economic Dynamics \& Control 33:725-744

Heijdra B, Romp WE (2009b) Retirement, pensions, and ageing. Journal of Public Economics 93:586-604

Hellwig M, Irmen A (2001) Endogenous technical change in a competitive economy. Journal of Economic Theory 101:1-39

A. Irmen (2018) Technological Progress, the supply of hours worked, and the consumption-leisure complementarity. CESifo working paper series 6843, CESifo group Munich 
Jones BF (2010) Age and great invention. The Review of Economics and Statistics 92:1-14

Krüger D, Ludwig A (2007) On the consequences of demographic change for rates of returns to capital, and the distribution of wealth and welfare. Journal of Monetary Economics 54:49-87

Lang K (2016) Perspective on "ageing and the skill portfolio: evidence from job based skill measures" by Bowlus AJ, Mori H, Robinson C (2016). Journal of the Economics of Ageing 7:104-105

Lee R, Mason A (2010) Fertility, human capital, and economic growth over the demographic transition. European Journal of Population 26:159-182

Lucas RE (1988) On the mechanics of economic development. Journal of Monetary Economics 22:3-42

Ludwig A, Schelkle T, Vogel E (2012) Demographic change, human capital and welfare. Review of Economic Dynamics 15:94-107

Madsen JB (2008) Semi-endogenous versus Schumpeterian growth models: testing the knowledge production function using international data. Journal of Economic Growth 13:1-26

N Maestas, KJ Mullen, D Powell (2016) The effect of population aging on economic growth, the labour force and productivity. NBER working paper 22452

Malik AK (2013) The effects of fiscal spending shocks on the performance of simple monetary policy rules. Economic Modelling 30:643-662

Mankiw NG, Romer D, Weil DN (1992) A contribution to the empirics of economic growth. Quarterly Journal of Economics 107:407-437

Mason A, Lee R, Jiang JX (2016) Demographic dividends. Human Capital, and Saving, The Journal of the Economics of Ageing 7:106-122

Mérette M, Georges P (2010) Demographic changes and the gains from globalisation: an analysis of ageing, capital flows, and international trade. Global Economy Journal 10:1-37

A Narciso (2010) The impact of population ageing on international capital flows, MPRA paper no. 26457, November

Peterman WB (2016) Reconciling micro and Macro estimates of the Frisch labour supply elasticity. Economic Inquiry 54:100-120

Prettner K, Canning D (2014) Increasing life expectancy and optimal retirement in general equilibrium. Economic Theory 56:191-217

Prettner K, Prskawetz A (2010) Demographic change in models of endogenous economic growth. A survey Central European Journal of Operations Research 18:593-608

Prettner K, Trimborn T (2017) Demographic change and R\&D-based economic growth. Economica 84:667-681

Rivera-Batiz LA, Romer PM (1991) Economic integration and endogenous growth. Quarterly Journal of Economics 106:531-555

Romer PM (2001) Should the government subsidize supply or demand in the market for scientists and engineers? Innovation Policy and the Economy 1:221-252

Roodman D (2009) A note on the theme of too many instruments. Oxford Bulletin of Economics and Statistics $71: 135-158$

Sasaki H, Hoshida K (2017) The effects of negative population growth: an analysis using a Semiendogenous R\&D Growth Model. Macroeconomic Dynamics 21:1545-1560

Strulik H (2005) The role of human capital and population growth in R\&D-based models of economic growth. Review of International Economics 13:129-145

Uzawa H (1965) Optimum technical change in an aggregative model of economic growth. International Economic Review 6:18-31

von Gaessler AE, Ziesemer T (2016) Optimal education in times of ageing: the dependency ratio in the Uzawa-Lucas growth model. The Journal of the Economics of Ageing 7:125-142

Wallenius J (2011) Human capital accumulation and the intertemporal elasticity of substitution of labour: how large is the bias? Review of Economic Dynamics 14:577-591

Zhang J, Zhang J, Lee R (2001) Mortality decline and long-run economic growth. Journal of Public Economics 80:485-507

Zhang J, Zhang J, Lee R (2003) Rising longevity, education, savings, and growth. Journal of Development Economics 70:83-101

Ziesemer T (1995) Growth with imported capital goods, limited export demand and foreign debt. Journal of Macroeconomics 17:31-53

Ziesemer THW (2020) Can we have growth when population is stagnant? Testing linear growth rate formulas of non-scale endogenous growth models. Applied Economics, 52(13), 1502-1516. https://doi. org/10.1080/00036846.2019.1676391

Publisher's note Springer Nature remains neutral with regard to jurisdictional claims in published maps and institutional affiliations. 